\title{
Synthesis of a Wheat/Maize Hybrid CENH3 Gene, the Genetic Transformation of Wheat, Its Chromosomal Localization and Effects on Chromosome Behaviors in Wheat/Maize Somatic Hybrids
}

\author{
Xiaoyu Yang1,2*, Jianhui $\mathrm{Li}^{3}$, Weichang $\mathrm{Yu}^{1^{*}}$ \\ ${ }^{1}$ Guangdong Provincial Key Laboratory for Plant Epigenetics, College of Life Sciences and Oceanography, Shenzhen University, \\ Shenzhen, China \\ ${ }^{2}$ Key Laboratory of Optoelectronic Devices and Systems of Ministry of Education and Guangdong Province, College of \\ Optoelectronic Engineering, Shenzhen University, Shenzhen, China \\ ${ }^{3}$ School of Life Sciences, State Key Laboratory of Agrobiotechnology, The Chinese University of Hong Kong, \\ Hong Kong, China \\ Email: *xyyang-1982@163.com, *wyu@szu.edu.cn
}

How to cite this paper: Yang, X.Y., Li, J.H. and Yu, W.C. (2019) Synthesis of a Wheat/ Maize Hybrid CENH3 Gene, the Genetic Transformation of Wheat, Its Chromosomal Localization and Effects on Chromosome Behaviors in Wheat/Maize Somatic Hybrids. Agricultural Sciences, 10, 985-1014. https://doi.org/10.4236/as.2019.107075

Received: June 22, 2019

Accepted: July 28, 2019

Published: July 31, 2019

Copyright ๑ 2019 by author(s) and Scientific Research Publishing Inc. This work is licensed under the Creative Commons Attribution International License (CC BY 4.0).

http://creativecommons.org/licenses/by/4.0/

cC) (i) Open Access

\begin{abstract}
Centromere-specific histone $\mathrm{H} 3$ (CENH3) replaces the canonical histone $\mathrm{H} 3$ in nucleosomes of functional centromeres, and plays important roles in faithful chromosome segregation during cell division. CENH3 is also important in the recognition of alien centromeres and determines the accommodation or elimination of alien chromosomes in interspecific or intergenic hybridization. In this study, a maize full length $\mathrm{CENH} 3$ with a yellow fluorescent protein $(Y F P)$ tag at C-terminus (ZmCENH3-YFP) and a synthetic hybrid $w m C E N H 3$ with the $\mathrm{N}$-terminus from wheat $\mathrm{CENH} 3$ and the histone fold domain (HFD) from maize tagged with a red fluorescent protein $(R F P)$ at the C-terminus (wmCENH3-RFP) were transformed to wheat by biolistics transformation. Transgenic wheat plants with both $Z m \mathrm{CNEH} 3-Y F P$ and $w m \mathrm{CENH} 3-$ $R F P$ genes were identified by PCR. The expression of ZmCENH3-YFP was not observed, while the expression of wmCENH3-RFP could be detected by RT-PCR, direct fluorescence microscopy, and immunostaining with anti-RFP antibody. The expressed wmCENH3-RFP was localized to nuclei as dotted patterns, indicating its targeting to wheat centromeres. Somatic hybridization was performed between $w m C E N H 3-R F P$ transgenic wheat and transgenic maize that expressed a $Z m C E N H 3-Y F P$ gene to investigate chromosome behaviors in somatic hybrids. Cytological and FISH analyses of somatic hybrid
\end{abstract}


cells showed the formation of micronuclei and lagging chromatin in both somatic hybridizations with or without the wmCENH3-RFP transgene, indicating that ectopically expressed wmCENH3 could not overcome chromosome elimination in wheat/maize somatic hybrids. Immunostaining of wmCENH3RFP and ZmCENH3-YFP in early stage somatic hybrid cells indicated that both wmCENH3-RFP and ZmCENH3-YFP proteins were expressed, but their binding patterns changed from the commonly observed dotted patterns to diffused ones, suggesting that the inactivation of $\mathrm{CENH} 3$ might be a factor for chromosome elimination in wheat/maize somatic hybridization.

\section{Keywords}

Centromeric Histone H3, Genetic Transformation, Chromosome Elimination, Somatic Hybridization, Wheat, Maize

\section{Introduction}

Centromeric histone $\mathrm{H} 3$ (CENH3) is a variant to replace canonical histone $\mathrm{H} 3$ nucleosome in functional centromere for kinetochore assembly. CENH3 is only $50 \%$ identical to canonical histone $\mathrm{H} 3$ in the histone fold domain (HFD) [1]. It plays an important role in chromosome behaviors during cell divisions, especially in chromosome elimination and adaptation. For example, haploid Arabidopsis plant could be produced by chromosome elimination when a wide type plant was crossed with a cenh3 mutant expressing an engineered CENH3 or naturally occurring CENH3 from distant related plant species [2] [3]. The chromosome elimination is always on chromosomes from the hybridization parent that expresses the divergent CENH3. Chromosome elimination has also been reported in the unstable interspecific barley hybrids caused by the loss of CENH3 protein and centromere inactivation [4]. In contrast, in the oat/maize addition lines, oat $\mathrm{CENH} 3$ can nucleate functional kinetochores on maize chromosomes while the maize CENH3 gene is silenced [5]. Thus, maize chromosomes can be retained in the oat genetic background.

Two regions of CENH3 protein are highly variable: N-terminal tail for kinetochore assembly and the loop 1 region which interacts with nucleosomal DNA and is crucial for centromere targeting and the recognition between CENH3 and centromeric DNA sequence [6] [7]. Domain swap experiments showed that chimeric CENH3 with the N-terminal tail from Lepidium oleraceum and the HFD from $A$. thaliana caused chromosome missegregation and genome elimination, while the reversely swapped chimeric $\mathrm{CENH} 3$ with the $A$. thaliana $\mathrm{N}$-terminal tail and the L.oleraceum HFD acted normally as the Arabidopsis CENH3[3]. Thus, the evolution of CENH3 could contribute to hybridization barrier that prevents genetic cross between distantly related plant species.

Hybridization barriers are generally divided into pre-zygotic and post-zygotic barriers [8]. Pre-zygotic barriers include spatial and temporal separation [9], 
morphologically and ethologically floral isolation [10], and failure in pollen-pistil interactions [11]. Technologies have been developed to overcome hybridization barriers to broaden genetic resources for plant breeding. For example, artificial hybridization could overcome some habitat, temporal and ethological barriers [8]; gametic barriers could be solved via in vitro fertilization technology, in which male and female gametes were isolate from reproductive organs of parental plants, and fused to produce zygotes through calcium-mediated, electrofusion or microinjection, and ion measurement methods [12]. Post-zygotic barriers include hybrid non-viability, weakness and sterility [13] [14], hybrid breakdown [15], and hybrid necrosis [16]. Post-zygotic barriers are mainly caused by aborted embryo or endosperm, abnormal chromosome behaviors, and selective chromosome elimination [17] [18]. Some techniques have been developed to tackle post-zygotic barriers. For example, chromosome doubling technique was developed to solve hybrid sterility [19], and embryo rescue technique was developed to recover unviable and weak hybrid embryos from abortion [20]. Somatic hybridization technique was also developed to generate somatic hybrids between sexually incompatible plants that could not be realized by conventional genetic cross.

Recent studies have revealed molecular mechanisms of chromosome elimination in hybridization barrier. The importance of CENH3 in chromosome eliminations hints that CENH3 might be manipulated to overcome chromosome eliminations. In wheat/maize hybrids from genetic cross and somatic hybridization, maize chromosomes are quickly eliminated during the first several cell cycles [21]-[26]. Chen et al. [27] reported an attempt to ectopically express a maize CENH3 gene $(Z m C E N H 3)$ in transgenic wheat. However, although the $\mathrm{ZmCENH} 3$ could be transcribed at a low level, $\mathrm{ZmCENH3}$ protein was not detected by both western blot and immunostaining. Chromosome elimination was not suppressed in genetic crosses between transgenic wheat and maize. To overcome the suppression of $Z m C E N H 3$ transgene expression in transgenic wheat, we synthesized a hybrid $w m \mathrm{CENH} 3$ gene, which has the $\mathrm{N}$-terminus before loop 1 domain from wheat TaCENH3, the C-terminal HFD after loop 1 from maize $Z m C E N H 3$, and a red fluorescent protein $(R F P)$ tag at the C-terminus. The synthesized $w m C E N H 3$ gene was cloned into a gene expression cassette under a strong maize ubiquitin promoter [28], and transformed into wheat by biolistic transformation. Transgenic wheat was generated and the influence of ectopically expressed wmCENH3 on chromosome behaviors in wheat/maize somatic hybrids was analyzed.

\section{Materials and Methods}

\subsection{Plant Materials}

"Bobwhite" bread wheat (Triticum aestivum L., $2 \mathrm{n}=6 \mathrm{x}=42$ ), a super-transformable inbred line, was used in this study. To induce wheat embryonic callus, sterilized immature embryos [29] were cultured on Induction medium contain- 
ing $4.4 \mathrm{~g} / \mathrm{L}$ MS mixture with vitamins, $30 \mathrm{~g} / \mathrm{L}$ sucrose, $0.2 \mathrm{~g} / \mathrm{L}$ casein, $0.146 \mathrm{~g} / \mathrm{L}$ glutamine, $2 \mathrm{mg} / \mathrm{L}$ 2, 4-D, $3 \mathrm{~g} / \mathrm{L}$ Gelrite ( $\mathrm{pH}$ 5.7). The induced wheat calli were kept in an incubator with air temperature of $28^{\circ} \mathrm{C}$ in darkness and subcultured every 4 weeks.

Transgenic $Z m C E N H 3$ - YFP maize seeds were kindly provided by Prof. James Birchler (University of Missouri, Columbia). Seeds were sowed in soil and kept in growth chamber with photoperiod of $16 \mathrm{~h}$, light intensity of $400-500$ $\mu \mathrm{mol} / \mathrm{m}^{2} / \mathrm{s}$, relative humidity of $70 \%$, air temperature of $28^{\circ} \mathrm{C}$ during the day and of $25^{\circ} \mathrm{C}$ during the night.

\subsection{Sequence Analysis}

To analyze the similarity of three different CENH3 proteins, amino acid sequences of TaCENH3, ZmCENH3 and a synthetic wmCENH3 were aligned with the canonical histone $\mathrm{H} 3$ of rice using the CLC Sequence Viewer 7.6 software program (https://www.qiagenbioinformatics.com/products/clc-sequence-viewer/).

\subsection{Constructs for Wheat Transformation}

The maize CENH3 gene with a YFP tag was constructed in pTF101, and was kindly provided by Prof. James Birchler (University of Missouri, Columbia). The pTF101-ZmCENH3-YFP (Figure 1(A)) had streptomycin resistance in E. coli, and two expression cassettes: a maize full length $\mathrm{CENH} 3$ gene with a $Y F P$ tag at C-terminus driven by $2 \times 35 \mathrm{~S}$ promoter from cauliflower mosaic virus (CaMV), and a Bargene driven by $2 \times 35 \mathrm{~S}$ promoter as the selectable marker.

A $w m C E N H 3-R F P$ gene was synthesized and cloned into the pCAMBIA3301 vector to construct pCAMBIA3301-wmCENH3-RFP (Figure 1(B)). This construct had kanamycin resistance in $E$. coli, and three expression cassettes on T-DNA region: a $w m C E N H 3-R F P$ gene with wheat TaCENH3 $\mathrm{N}$-terminus before Loop1 domain, the maize $Z m C E N H 3$ C-terminus after Loop1, and a $R F P$ gene tag at C-terminus, driven by a maize ubiquitin promoter [28]; a Bar gene driven by $2 \times 35 \mathrm{~S}$ promoter from cauliflower mosaic virus as the selectable marker; and a $\beta$-glucuronidase (GUS) gene [30] driven by $35 \mathrm{~S}$ promoter as the reporter gene.

\subsection{Biolistic Transformation of Wheat and Plant Regeneration}

Plasmid DNAs were extracted by alkaline extraction method [31], and purified with QIAprep Spin miniprep Kit according to the manufacturer's protocol. $1 \mu \mathrm{g}$ plasmid DNA of pCAMBIA3301-wmCENH3-RFP or pTF101-ZmCENH3-YFP was coated to $1.5 \mathrm{mg}$ ( $1 \mu \mathrm{m}$ diameter) gold particles (Bio-Rad) according to the protocol of Gold Particle Preparation for Bombardment developed by the Iowa State University Plant Transformation Facility (http://ptf.agron.iastate.edu/protocol/Gold\%20Particle.pdf). Wheat embryonic calli were pre-treated at $25^{\circ} \mathrm{C}$ for $4-6 \mathrm{~h}$ in Osmotic medium (Induction medium supplemented with $36.44 \mathrm{~g} / \mathrm{L}$ mannitol and $36.44 \mathrm{~g} / \mathrm{L}$ sorbitol), and bombarded 
(A)

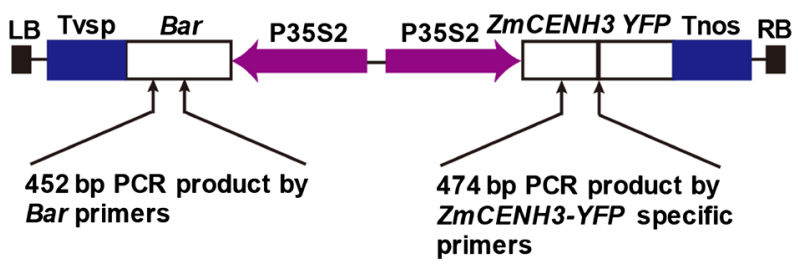

(B)

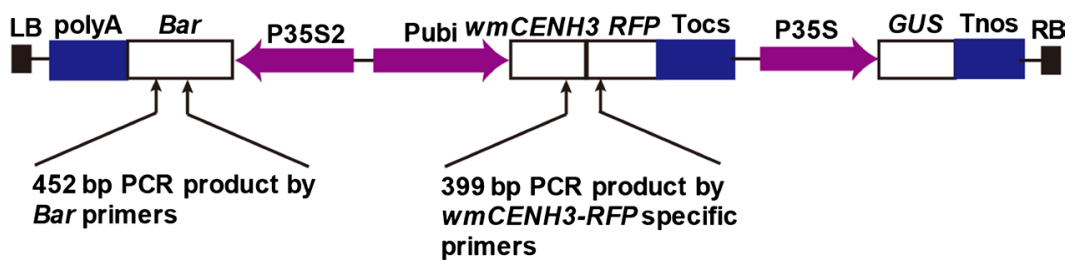

Figure 1. CENH3 constructs for wheat transformation. (A) pTF101-ZmCNEH3-YFP construct contains a Bialaphos resistance gene (Bar) gene driven by a $2 \times 35 \mathrm{~S}$ (P35S2) promoter as the selection marker, and a $Z m C E N H 3-Y F P$ gene driven by the P35S2 promoters; (B) pCAMBIA3301-wmCENH3-RFP construct contains a Bar gene driven by the P35S2 promoter as the selection marker, a wmCENH3-RFP gene driven by a constitutive maize Ubi promoters (Pubi), and a GUS gene driven by a cauliflower mosaic virus ( CaMV) 35S promoter (P35S). LB and RB are the T-DNA left and right border sequences, respectively; Tnos, Tocs, Tvsp, and polyA are terminators from Agrobacterium nopaline synthase gene, Agrobacterium octopine synthase gene, soybean vegetative storage protein gene and the polyA sequences from CaMV 35S RNA, respectively; $G U S$ is the $\beta$-glucuronidase reporter gene; YFP and RFP are yellow and red fluorescence protein genes, respectively; $Z m C E N H 3$ is the maize full length CENH3 gene; $w m C E N H 3$ is a synthetic CENH3 gene with the N-terminal tail from wheat TaCENH3 and the C-terminal part from maize $Z m C E N H 3$ gene. The arrows point to the sites of primers used for PCR identification of transgenic plants with transgenes of Bar, $Z m \mathrm{CENH} 3-Y F P$, and $w m \mathrm{CENH} 3-R F P$, respectively. The size of each PCR product is indicated.

with a Bio-Rad PDS 1000/He particle delivery system according to the previous protocol [32] with the following parameters: 1300 psi delivery pressure of helium tank and 1100 psi rupture disc. Petri dish with calli in the center was placed on level 4 of sample holder in Bio-Rad PDS/1000 He, and the distance between macrocarriers and calli was $12 \mathrm{~cm}$.

The transformed calli were treated at $25^{\circ} \mathrm{C}$ in Osmotic medium for $16-20 \mathrm{~h}$ after bombardment, and transferred to culture in the dark at $25^{\circ} \mathrm{C}$ for 2 weeks in Selection medium I (Induction medium without glutamine and casein). The proliferated calli were then cultured in the dark at $25^{\circ} \mathrm{C}$ for 3 months in Selection medium II (Selection medium I supplemented with $5 \mathrm{mg} / \mathrm{L}$ Bialaphos) for positive calli selection. The Bialaphos resistant calli were transferred onto Regeneration medium (Selection medium without 2, 4-D, supplemented with 0.5 $\mathrm{mg} / \mathrm{L}$ 6-BA, $0.1 \mathrm{mg} / \mathrm{L} \mathrm{IAA}$, and $2 \mathrm{mg} / \mathrm{L}$ Bialaphos), and cultured at $25^{\circ} \mathrm{C}$ in Plant Tissue Culture Chamber (Percival Scientific Inc. CU-36L4 HOSTC Limited) with the photoperiod of $16 \mathrm{~h}$ to induce shoots. The regenerated green plantlets were transferred to Rooting medium (Selection medium I without 2, 4-D) for 
plantlets to develop at $25^{\circ} \mathrm{C}$ with the photoperiod of $16 \mathrm{~h}$. Well-developed plantlets were washed to remove the attached medium on roots with tap water, and handled carefully to avoid damaging the roots. Plantlets with white and healthy roots were planted in pots and cultured in growth chamber according to the previous method [33] with high humidity for plants acclimatization during the first week. The transgenic plants were growing in the growth chamber until maturity and self-pollinated to produce seeds.

\subsection{Genomic DNA Isolation from Transgenic Wheat}

Genomic DNAs were isolated from wild type and transgenic wheat lines by SDS method [34] with modification. $1 \mathrm{~g}$ of leaf samples was placed in a mortar and ground by a pestle to a fine powder after treated with liquid nitrogen. The frozen powder was then transferred to 2-ml tubes containing $1 \mathrm{ml}$ DNA extraction buffer [0.5 M NaCl, 0.1 M Tris-HCl, 0.05 M EDTA and 0.6\% (w/v) SDS, pH 8.0] for DNA extraction. Genomic DNA was precipitated by equal volumes of isopropanol and centrifugation. DNA pellets were re-suspended with $0.6 \mathrm{ml}$ of $1 \mathrm{M}$ $\mathrm{NaCl}$ after centrifugation at $5000 \mathrm{rpm}$ for $10 \mathrm{~min}$ at room temperature. 1 volume of chloroform was added to DNA solution, mixed well and centrifuged at 12,000 $\mathrm{rpm}$ at room temperature for $10 \mathrm{~min}$. The supernatants were transferred to $1.5-\mathrm{ml}$ tubes and DNAs were precipitated with 1 volume of isopropanol at $-20^{\circ} \mathrm{C}$. DNA pellets were washed with $500 \mu \mathrm{L}$ of $70 \%(\mathrm{v} / \mathrm{v})$ ethanol, air-dried and then dissolved in $50 \mu \mathrm{L}$ of sterilized Milli-Q water containing 10 units RNase A for $5 \mathrm{~min}$ at room temperature. The quantity and quality of genomic DNAs were determined by gel electrophoresis.

\subsection{Identification of Transgenic Wheat Plants by PCR}

PCR was performed with three sets of primers: 1) P1 (5'-GCACCATCGTCAAC CACTAC-3') and P2 (5'-TACCGGCAGGCTGAAGTCCA-3') for 452 bp Bar fragment, 2) P3 (5'-AAGGATCCATGGCTCGAACCAAGC-3') and P4 (5'-AAG AGCTCTCATGCCCAACGCCTT-3') for 474 bp $Z m C E N H 3$ - $Y F P$ fragment, 3) P5 (5'-AGAGCGCTATACCGCAGAAG-3') and P6 (5'-GGGTGCTTCACGTA CACCTT-3') for $399 \mathrm{bp} w m$ CENH3-RFP fragment.

PCR reactions were performed in a total volume of $20 \mu \mathrm{L}$ containing $10 \mu \mathrm{L}$ Premix Ex Taq Hot Start Version (Takara Code No. HRR030A), 50 ng wheat genomic DNA or $10 \mathrm{ng}$ plasmid DNA, $0.5 \mu \mathrm{M}$ each of forward and reverse primers with the following PCR program: an initial denaturalization at $95^{\circ} \mathrm{C}$ for 3 min, 35 cycles of denaturalization at $98^{\circ} \mathrm{C}$ for $10 \mathrm{~s}$, annealing at $60^{\circ} \mathrm{C}$ for $30 \mathrm{~s}$ and extension at $72^{\circ} \mathrm{C}$ for $40 \mathrm{~s}$, followed by a final extension at $72^{\circ} \mathrm{C}$ for $5 \mathrm{~min}$. PCR products were checked on $0.8 \%$ agarose gel after staining by ethidium bromide (EB).

\subsection{Southern Blot for T0 Transgenic Wheat Lines}

Southern blot analysis was performed to confirm gene transformation in T0 
transgenic wheat. $20 \mu \mathrm{g}$ of genomic DNA per sample was digested with 150 units of restriction enzyme, $E c o R$ I, at $37^{\circ} \mathrm{C}$ overnight, fractioned in a $1.0 \%(w / v)$ agarose gel at $60 \mathrm{v}$ for $4 \mathrm{~h}$, denatured and transferred to Hybond $\mathrm{N}+$ membranes. A digoxygenin (DIG) labeled Bar gene DNA fragment was synthesized by PCR with the Bar primers of P1/P2 and used as the probe. Prehybridization, washing, and chemiluminescent detection of the blots were performed according to the manufacturer's instructions (Roche Diagnostics GmbH, Mannheim, Germany).

\subsection{Expression Analysis of wmCENH3-RFP in Transgenic Wheat}

RT-PCR was performed in T0 transgenic wheat for the detection of wmCENH3$R F P$ expression. Total RNA isolation from leaves of wild type and wmCENH3$R F P$ transgenic wheat was performed by using an RNeasy Plant Mini Kit (QIAGEN) according to the manufacturer's instruction. The first strand cDNA synthesis was performed using PrimeScript RT-PCR Kit (Takara). PCR amplification was performed using primers of P5 (5'-AGAGCGCTATACCGCAGAAG-3') and P6 (5'-GGGTGCTTCACGTACACCTT-3') for wmCEHN3-RFP gene with the same program mentioned above. The PCR products were separated by $2 \%$ agarose gel electrophoresis and stained with EB for visualization.

\subsection{Localization of Alien CENH3 Protein by Fluorescence Microscopy}

Root tips of transgenic wheat were squashed on glass slides with cover glasses, and examined for red or yellow fluorescence under the $100 \times$ oil immersion objective of Leica DM5500B fluorescence microscope (Leica Microsystems). Images were captured with a Leica DFC490 digital camera and processed by Adobe Photoshop CS software.

\subsection{Immunostaining of wmCENH3-RFP in Transgenic Wheat}

Root tips of wild type wheat and T0 transgenic wheat lines (11-1, C2901, C3057 and C3216) were checked for the expression of wmCENH3-RFP by immunostaining [5] with some modifications. The root tips were treated with $\mathrm{N}_{2} \mathrm{O}$ at 1000 psi for $2 \mathrm{~h}$, and fixed in $4 \%(\mathrm{v} / \mathrm{v})$ paraformaldehyde in $1 \times$ phosphate buffered saline (PBS, $8.1 \mathrm{mM} \mathrm{Na}_{2} \mathrm{HPO}_{4}, 1.5 \mathrm{mM} \mathrm{KH}_{2} \mathrm{PO}_{4}, 2.7 \mathrm{mM} \mathrm{KCl}, 136 \mathrm{mM} \mathrm{NaCl}$ ) with $0.2 \%(\mathrm{v} / \mathrm{v})$ Triton X-100 for $30 \mathrm{~min}$. After being washed three times with 1 $\times$ PBS, the fixed root tips were transferred to a tube containing $20 \mu$ enzymatic solution [2\% (w/v) Cellulase Onozuka R-10 and 1\% (w/v) Pectolyase Y-23 in $1 \times$ PBS] in water bath at $37^{\circ} \mathrm{C}$ for $1 \mathrm{~h}$. The digested root tips were washed three times with $1 \times$ PBS, broken down with a needle, and separated by vortex for $20 \mathrm{~s}$. The separated cells were pelleted by centrifugation and re-suspended in $50 \mu \mathrm{L}$ of $1 \times$ PBS by vortex. A total of $10 \mu \mathrm{l}$ of digested cells was dropped onto a Poly-L-Lysine coated microscope slide and dried for $4 \mathrm{~h}$ in a water-wetted box. $10 \mu \mathrm{l}$ of rabbit anti-RFP antibody [diluted at 1:100 in blocking solution (5\% BSA, $0.3 \%$ Triton $\mathrm{X}-100$ in $\mathrm{PBS})]$ was added to slides with chromosomes of wmCENH3-RFP 
transgenic wheat. After incubated at $4^{\circ} \mathrm{C}$ overnight, slides were washed three times in $1 \times$ PBS and detected by using sheep anti-rabbit Ig-Rhodamine (Millipore) secondary antibody (1:100 dilution in blocking solution). The slides were incubated for $2 \mathrm{~h}$ at room temperature and washed three times in $1 \times \mathrm{PBS}$, mounted with a drop of Vectashield (Vector Laboratories) containing $1.5 \mu \mathrm{g} / \mathrm{ml}$ DAPI and examined under the $100 \times$ oil immersion objective of Leica DM5500B fluorescence microscope. Images were captured with a Leica DFC490 digital camera and processed with PHOTOSHOP CS software.

\subsection{Establishment of Cell Suspension Culture for Wheat}

Wild type or $w m C E N H 3-R F P$ transgenic wheat calli were used to initiate cell suspension cultures in $150 \mathrm{ml}$ flasks containing $50 \mathrm{ml}$ liquid Induction medium or Selection medium I, respectively. Suspension cells were subcultured every $4 \mathrm{~d}$ to stimulate vigorous growth until abundant, fine and white cell clusters appeared in liquid medium in about 1 month. Large cell clusters were removed by filtering through $1 \mathrm{~mm}$ pore sized metal sieves, and small cell clusters were kept and subcultured every $4 \mathrm{~d}$ until the establishment of wheat cell suspension cultures. The suspension cultures were incubated in an IS-KDD3 Table Shaker (CRYSTAL, Product number 1109012) at $28^{\circ} \mathrm{C}$ in the dark with $130 \mathrm{rpm}$ rotation.

\subsection{Protoplast Isolation from Wheat and Maize}

For isolation of wheat protoplast, a mixture of $6 \mathrm{ml}$ enzyme solution [3\% (w/v) Cellulose Onozuka R-10, 1.5\% (w/v) Macerozyme R-10, 0.5\% (w/v) Pectolyase Y-23, $12.8 \%$ (w/v) mannitol, $0.36 \%(w / v) \mathrm{CaCl}_{2} \cdot 2 \mathrm{H}_{2} \mathrm{O}, 0.11 \%$ (w/v) $\mathrm{NaH}_{2} \mathrm{PO}_{4}$, $0.12 \%(\mathrm{w} / \mathrm{v})$ MES hydrate, $\mathrm{pH} 5.6$ ] and $6 \mathrm{ml}$ P5 liquid medium (4.4 g/L MS with vitamins, $0.5 \mathrm{mg} / \mathrm{L}$ nicotinic acid, $0.5 \mathrm{mg} / \mathrm{L}$ pyridoxine- $\mathrm{HCl}, 9.9 \mathrm{mg} / \mathrm{L}$ thiamine-HCl, $1 \mathrm{mg} / \mathrm{L} 2,4-\mathrm{D}, 0.146 \mathrm{~g} / \mathrm{L}$ glutamine, $0.5 \mathrm{~g} / \mathrm{L}$ casein hydrolysate, 2 $\mathrm{mg} / \mathrm{L}$ glycine, $90 \mathrm{~g} / \mathrm{L}$ glucose, $10 \mathrm{~g} / \mathrm{L}$ sucrose, $\mathrm{pH}$ 5.8) was added to a $50-\mathrm{ml}$ flask with about $3 \mathrm{~g}$ of suspension cells for digestion in an incubator shaker at $30^{\circ} \mathrm{C}$ in darkness for $16 \mathrm{~h}$ or overnight with $45 \mathrm{rpm}$ rotation. After enzymatic digestion, cells were passed through $250 \mu \mathrm{m}$ and $45 \mu \mathrm{m}$ sterile metal-mesh sieves, collected in a $15-\mathrm{ml}$ centrifuge tube, and centrifuged at $100 \mathrm{~g}$ for $5 \mathrm{~min}$. Supernatant was removed with Pasteur pipettes and protoplast pellets were re-suspended in $6 \mathrm{ml}$ CPW 25S [250 g/L sucrose in CPW buffer $\left(27.2 \mathrm{mg} / \mathrm{L} \mathrm{KH}_{2} \mathrm{PO}_{4}, 100 \mathrm{mg} / \mathrm{L} \mathrm{KNO}_{3}\right.$, $250 \mathrm{mg} / \mathrm{L} \mathrm{MgSO}{ }_{4} \cdot 7 \mathrm{H}_{2} \mathrm{O}, 150 \mathrm{mg} / \mathrm{L} \mathrm{CaCl}_{2} \cdot 2 \mathrm{H}_{2} \mathrm{O}, 0.2 \mathrm{mg} / \mathrm{L} \mathrm{KI}, 0.0025 \mathrm{mg} / \mathrm{L} \mathrm{Cu}-$ $\left.\left.\mathrm{SO}_{4} \cdot 5 \mathrm{H}_{2} \mathrm{O}, \mathrm{pH} 5.8\right)\right]$ solution by carefully bubbling. $2 \mathrm{ml} \mathrm{CPW} 13 \mathrm{M}(130 \mathrm{~g} / \mathrm{L}$ mannitol in CPW buffer) solution was added gently to the tube to avoid breaking the sucrose layer, centrifuged at $100 \mathrm{~g}$ for $5 \mathrm{~min}$, and then carefully transferred protoplast band between sucrose and mannitol layers to a new $15-\mathrm{ml}$ centrifuge tube. Protoplasts were re-suspended in $13 \mathrm{ml}$ P5 liquid medium with Pasteur pipettes and centrifuged at $100 \mathrm{~g}$ for $5 \mathrm{~min}$. The wheat protoplasts were washed two more times with P5 medium, and re-suspended in 10 volumes of P5 medium for protoplast fusion. 
To isolate maize protoplasts, young leaves of $Z m C E N H 3-Y F P$ transgenic maize seedlings were surface-sterilized by $0.625 \%(\mathrm{w} / \mathrm{v})$ sodium hypochlorite for 10 min, followed by being washed with $70 \%(\mathrm{v} / \mathrm{v})$ ethanol for $30 \mathrm{~s}$, and then rinsed 3 times with sterilized Milli-Q $\mathrm{H}_{2} \mathrm{O}$. Sterilized leaves were cut into $0.5 \mathrm{~mm}$ segments [35] and transferred to a flask with $12 \mathrm{ml}$ enzyme solution containing $2 \%$ $(\mathrm{w} / \mathrm{v})$ Cellulose Onozuka R-10, 0.1\% (w/v) Pectolyase Y-23 dissolved in MaCa solution (0.2 M mannitol and $80 \mathrm{mM} \mathrm{CaCl}_{2}$ ) [36]. After vacuumed for $15 \mathrm{~min}$, the flasks were wrapped with aluminum foil and placed on an incubator shaker with $45 \mathrm{rpm}$ rotation at $30^{\circ} \mathrm{C}$ in the dark for $4 \mathrm{~h}$. After filtration through $250 \mu \mathrm{m}$ and $45 \mu \mathrm{m}$ sieves, maize mesophyll protoplasts were transferred to a $15-\mathrm{ml}$ centrifuge tube, washed twice with MaCa solution, and re-suspended in 10 volumes of P5 liquid medium.

The qualities of wheat and maize protoplasts were checked under bright field inverted microscope (Nikon, TE300) immediately after isolation and images were captured with a digital camera (V-Tphoto adapter Nikon MBB74700).

\subsection{Symmetric Hybridization between Wheat and Maize}

The protoplast fusion between wmCENH3-RFP transgenic wheat line C3216 and $Z m C E N H 3$ - YFP transgenic maize was performed by PEG-mediated somatic hybridization [25] [37] [38]. After re-suspending wheat and maize pellets in P5 medium, wheat and maize protoplasts were mixed together at a ratio of $1: 1(\mathrm{v} / \mathrm{v})$ in a $15-\mathrm{ml}$ centrifuge tube. Four drops of protoplasts mixture were added to the center of a $30 \times 10 \mathrm{~mm}$ Petri dish for fusion. Two drops of $40 \%$ (w/v) PEG were added to the center of protoplast mixture and the fusion lasted for 15 min. After 15-min fusion, 2 drops of the mixture of fusion solution A and B at a ratio of 9:1 (v/v) were added to the opposite side of protoplast mixture to enhance fusion efficiency, and incubated for $15 \mathrm{~min}$. Then 12 drops of P5 medium were added around protoplast mixture to wash the protoplasts for 10 min. P5 medium was gently removed without disturbing the protoplasts. The protoplasts were washed 2 more times with P5 medium for 15 min each time. Ten drops of $\mathrm{P} 5$ medium were added to the top of fusion products. The plates were sealed and cultured at $28^{\circ} \mathrm{C}$ in the dark. Fusion products were checked under bright field of inverted microscope (Nikon, TE300) during culture period and images were captured with a digital camera (V-Tphoto adapter Nikon MBB74700).

\subsection{Cytological Analysis of Cell or Cell Clusters from Protoplast Fusion}

The cell cultures from the fusion protoplasts of wheat and maize were fixed at 7 , 14 and $28 \mathrm{~d}$ after fusion with Carnoy's fixative solution [39]. To fix the cells, P5 liquid medium in the plate was removed, and the cells were rinsed gently (not to disturb cells) 3 times with sterile Milli-Q $\mathrm{H}_{2} \mathrm{O}$. Carnoy's fixative solution was added to cells in the plates to fix at room temperature for $3 \mathrm{~h}$. The fixed cells 
were stored in $70 \%(\mathrm{v} / \mathrm{v})$ ethanol at $4^{\circ} \mathrm{C}$ in the dark until using.

Fixed cells were spread on slides by squash method [40]. They were removed from $70 \%(\mathrm{v} / \mathrm{v})$ ethanol, rinsed 3 times with sterile Milli-Q $\mathrm{H}_{2} \mathrm{O}$, and stained with a drop of $2 \%$ Aceto-Orcein. Then $5 \mu \mathrm{L}$ cells were loaded to an ethanol washed slide, covered with a cover glass, and separated by gently knocking cover glass with the round end of a dissecting needle. A blotting paper was placed over the slide and squashed upright with thumb. Cells were observed under $20 \times$ objective of Nikon light microscope (E80i), and images were captured with a digital camera (RTKE SPOT).

\subsection{FISH Analysis of Cell or Cell Clusters from Somatic Hybridization}

The maize B repeat sequence [41] was found to specifically hybridize to the subtelomeres of wheat chromosomes (Supplementary Figure S1), thus was used to visualize wheat chromosomes in this study. Maize CentC [42] and B repeat sequences were amplified by PCR. The amplified CentC and B repeat DNAs were labeled with Chroma Tide Alexa Fluor 488-5-dUTP and Chroma Tide Alexa Fluor 594-5-dUTP (Invitrogen) respectively, by nick translation [43] [44].

FISH analysis of fixed cell or cell clusters from protoplast fusion were performed according to previous methods [44] [45] with some modifications. Fixed cell or cell clusters were removed from $70 \%(\mathrm{v} / \mathrm{v})$ ethanol, rinsed 3 times with sterile Milli-Q $\mathrm{H}_{2} \mathrm{O}$, transferred to enzyme solution [1\% (w/v) Pectolyase Y-23, $2 \%\left(\mathrm{w} / \mathrm{v}\right.$ ) Cellulase R-10], kept on the ice for $10 \mathrm{~min}$, and then incubated at $37^{\circ} \mathrm{C}$ in water bath for $1 \mathrm{~h}$. The digested cells were washed twice with $70 \%(\mathrm{v} / \mathrm{v})$ ethanol to remove enzyme solution, broken down with a needle, and separated by vortex for 20 s. The separated cells were pelleted by centrifugation and re-suspended in $50 \mu \mathrm{L}$ $100 \%$ acetic acid by vortexing. Then $5 \mu \mathrm{L}$ cells were dropped onto a glass slide inside a water-wetted box to let the nuclei/chromosomes spread and dry on the slide surface. The slide was crosslinked with $0.1 \mathrm{~J}$ UV light. A mixture of maize CentC and B repeat probes containing 100 ng labeled DNA each were added to each slide. The slide with probes was denatured in a metal box in boiling water for $5 \mathrm{~min}$, and hybridized at $55^{\circ} \mathrm{C}$ overnight in the dark. After hybridization, slides were washed with $2 \times$ SSC at room temperature for $5 \mathrm{~min}$, followed by 20 -min washing with $2 \times \mathrm{SSC}$ at $55^{\circ} \mathrm{C}$. Nuclei/chromosomes were stained with $10 \mu \mathrm{L}$ mounting medium with DAPI (Vectashield, H-1200), and observed under the $100 \times$ oil immersion objective of Leica DM5500B fluorescence microscope (Leica Microsystems). Images were captured with a Leica DFC490 digital camera and processed by Adobe Photoshop CS software.

\subsection{Immunostaining of CENH3 in Somatic Hybridized Cells}

High-frequency chromosome elimination usually occurs during the 10 - $14 \mathrm{~d}$ after protoplast fusion [46]. To analyze the CENH3 behavior during chromosome elimination of $w m \mathrm{CENH} 3-R F P$ transgenic wheat/ZmCENH3-YFP transgenic 
maize somatic hybrids, cell or cell clusters were sampled 11 - $14 \mathrm{~d}$ after protoplast fusion and the localizations of wmCENH3-RFP and ZmCENH3-YFP were analyzed by immunostaining. Cultured cells in microplates were collected in a 2 - $\mathrm{ml}$ tube by centrifugation at $2000 \mathrm{~g}$ for $5 \mathrm{~min}$. After 30-min fixation in $4 \%$ $(\mathrm{v} / \mathrm{v})$ paraformaldehyde in fresh full-strength PBS, cells were collected by centrifugation at $2000 \mathrm{~g}$ for $5 \mathrm{~min}$ and washed with $1 \times \mathrm{PBS}$ containing $0.2 \%(\mathrm{v} / \mathrm{v})$ Triton X-100. The fixed cells were digested in $20 \mu \mathrm{l}$ of enzyme solution containing $2 \%(\mathrm{w} / \mathrm{v})$ Cellulase Onozuka R-10, 1\% (w/v) Pectolyase Y-23 in $1 \times$ PBS at $37^{\circ} \mathrm{C}$ for $30 \mathrm{~min}$. Digested cells were vortexed at low speed for about $20 \mathrm{~s}$, centrifuged with a mini-centrifuge at $1500 \mathrm{~g}$ for $20 \mathrm{~s}$, washed 3 times with $200 \mu \mathrm{l} 1 \times$ PBS and re-suspended in a final volume of $15 \mu \mathrm{l} 1 \times$ PBS. A total of $10 \mu \mathrm{l}$ of digested cells was dropped onto a Poly-L-Lysine coated microscope slide and dried for $4 \mathrm{~h}$ in a water-wetted box. The wmCENH3-RFP and ZmCENH3-YFP proteins were detected with rabbit anti-RFP and mouse anti-GFP primary antibodies followed by sheep anti-rabbit Ig-Rhodamine (Millipore) secondary antibody (1:100 dilution in blocking solution) and FITC anti-mouse secondary antibody (Santa Cruz Biotechnology; 1:100 dilution in blocking solution), respectively. The slides were incubated for $2 \mathrm{~h}$ at room temperature, washed 3 times in $1 \times$ PBS, mounted with a drop of Vectashield (Vector Laboratories) containing 1.5 $\mu \mathrm{g} / \mathrm{ml} \mathrm{DAPI}$, and examined under the $100 \times$ oil immersion objective of Leica Leica DM5500B fluorescence microscope. Images were captured with a Leica DFC490 digital camera and processed with PHOTOSHOP CS software.

\section{Results}

\subsection{Sequence Analysis of Wheat and Maize CENH3 and the Design of a Synthetic wmCENH3}

Sequence alignment of wheat, maize and rice $\mathrm{CENH} 3$ proteins were performed (Figure 2(A)). The result showed conserved and diverged regions among the CENH3 proteins. The N-terminal regions were highly diverged among the CENH3 proteins, whereas the HFDs including $\alpha \mathrm{N}$-helix, $\alpha 1$-helix, Loop 1, $\alpha 2$-helix, Loop2 and $\alpha 3$-helix were relatively conserved.

The large divergence between wheat and maize CENH3 proteins ( $74 \%$ similarity) could be a factor for the suppression of $\mathrm{ZmCENH3}$ expression in transgenic wheat [27]. To reduce the difference between transgenic CENH3 and the endogenous $\mathrm{TaCENH} 3$, a synthetic $w m \mathrm{CENH} 3$ gene was designed to have the $\mathrm{N}$-terminus of TaCENH3 before the loop 1 domain, and the C-terminus of ZmCENH3 after loop 1 (Figure 2(B)). The synthetic wmCENH3 protein had 95\% similarity to the TaCENH3. An RFP tag was fused in frame to the C-terminus of the synthetic $w m \mathrm{CENH} 3$ gene to trace the behavior of the wmCENH3 in transgenic plants.

\subsection{Biolistic Transformation of Wheat and Plant Regeneration}

Wheat plants were grown in Plant Growth Chamber and 3900 immature embryos 
(A)

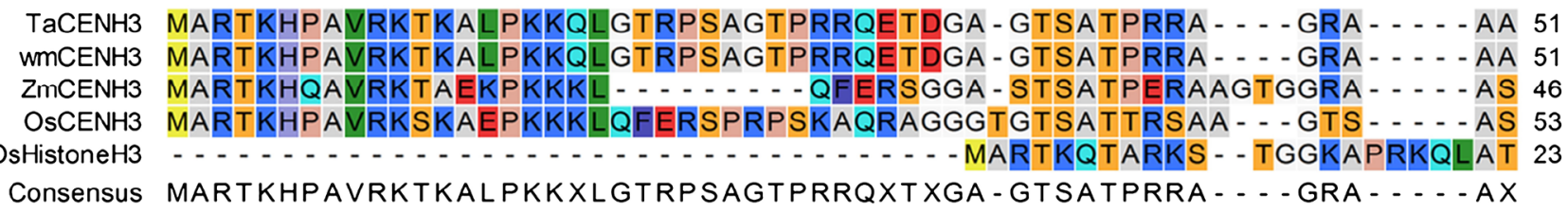
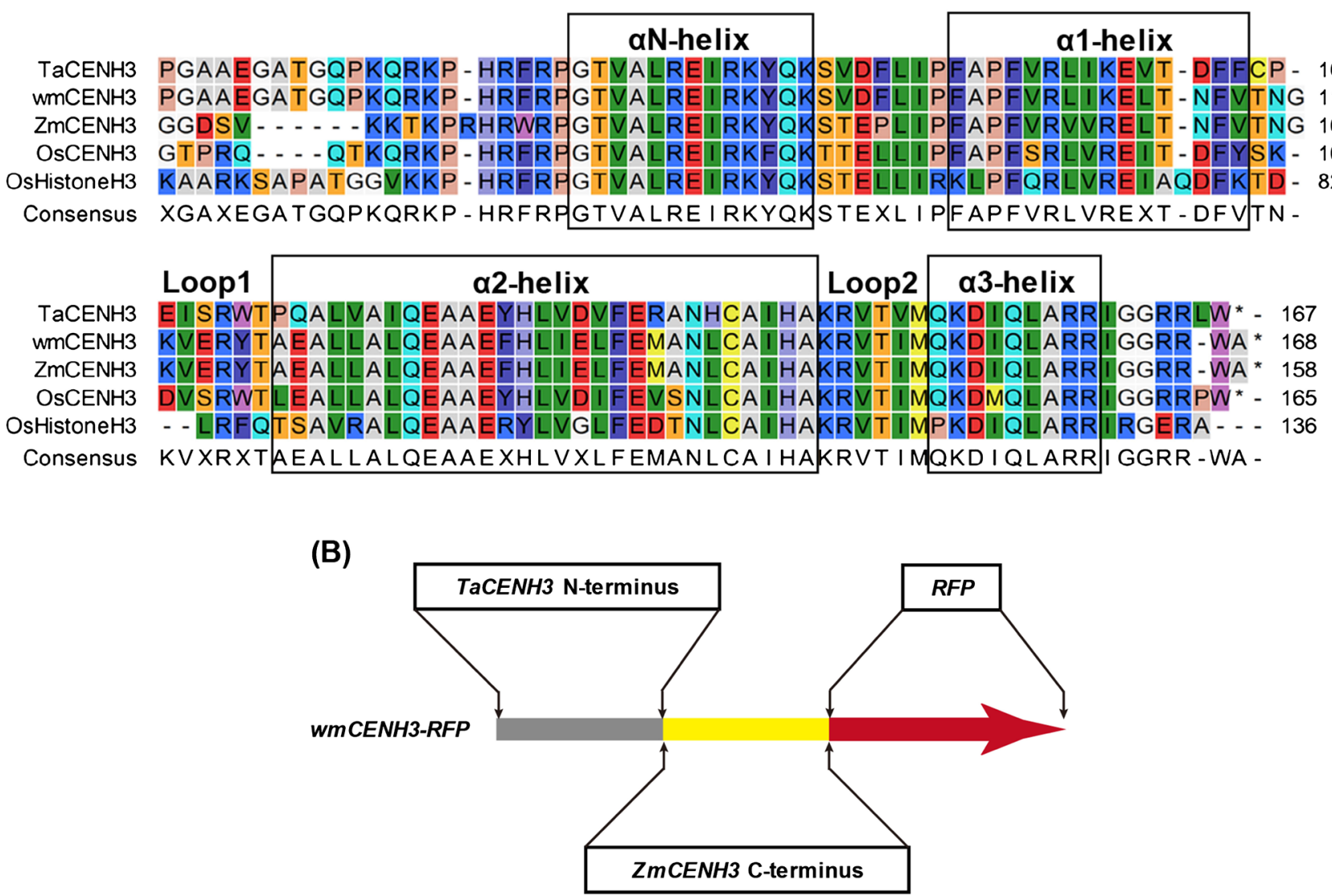

Figure 2. Alignment of CENH3s from wheat (TaCENH3), maize (ZmCENH3), rice (OsCENH3), the synthetic wmCENH3, and a rice canonical histone $\mathrm{H} 3$ (OsHistoneH3) (A) and the schematic diagram of the synthetic wmCENH3-RFP fusion protein (B). The conserved $\alpha \mathrm{N}, \alpha 1, \alpha 2$ and $\alpha 3$ helix domains are boxed. The two loop regions (Loop 1 and Loop 2) are indicated. The synthetic wmCENH3-RFP is a fusion protein composed of N-terminal region of wheat CENH3 (TaCENH3) before Loop1, the C-terminal region of maize CENH3 ( $\mathrm{ZmCENH3)} \mathrm{after} \mathrm{Loop1,} \mathrm{and} \mathrm{a} \mathrm{red} \mathrm{fluorescence} \mathrm{protein} \mathrm{(RFP)} \mathrm{tag} \mathrm{fused} \mathrm{in} \mathrm{frame} \mathrm{to} \mathrm{the} \mathrm{C-terminus} \mathrm{of}$ the wmCENH3 protein.

were collected aseptically, placed on Induction medium for 2 weeks for callus initiation (Figure 3(A)), and transformed by particle bombardment. Transformed calli were transferred to Selection medium supplemented with $5 \mathrm{mg} / \mathrm{L}$ Bialaphos and cultured at $25^{\circ} \mathrm{C}$ without light. The calli were subcultured every 3 - 4 weeks under selection conditions until resistant calli emerged. During Bialaphos selection, untransformed calli did not turn dark or brown, but they just grew slowly as compared with transformed ones. After several rounds of Bialaphos selection, fast growing calli (Figure 3(B) and Figure 3(C)) were transferred to Regeneration medium, and cultured at $25^{\circ} \mathrm{C}$ with $16 \mathrm{~h}$ photoperiod until plantlets regenerated (Figure 3(D)). 


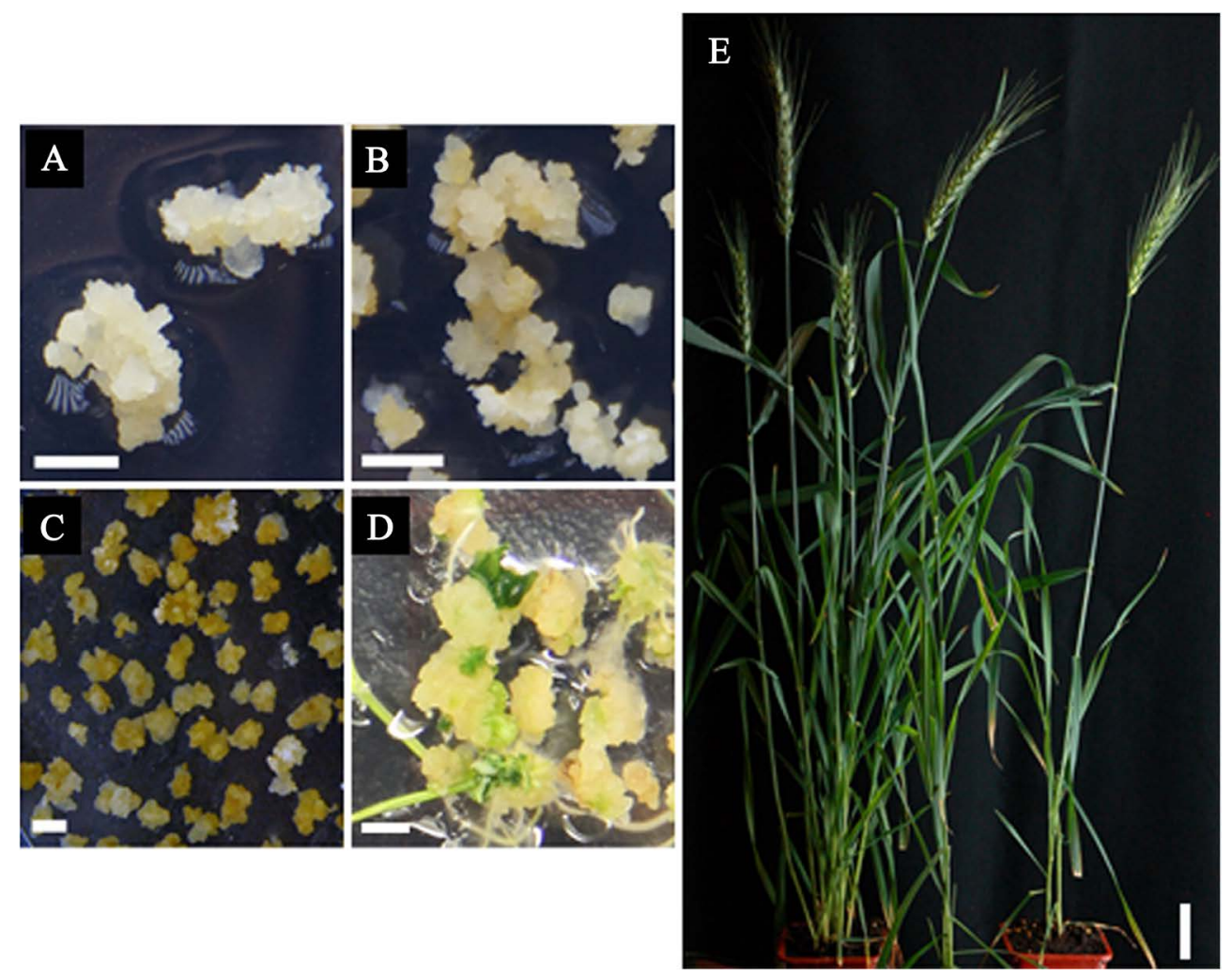

Figure 3. Genetic transformation and regeneration of transgenic wheat. (A) Wild type (WT) wheat calli induced from immature embryos; (B) Transformed wheat calli on Selection medium; (C) Resistant wheat calli on Regeneration medium; (D) Plantlets regenerated from resistant calli; (E) $w m$ CENH3-RFP transgenic wheat plants. Scale bars $=0.5 \mathrm{~cm}$ for ((A)-(D)) and $4 \mathrm{~cm}$ for $(\mathrm{E})$.

GUS staining was performed for fast growing callus lines C2901, C3057, C3216, C3455 and C3684 transformed with pCAMBIA3301-wmCENH3-RFP. The result suggested that not all cells in the calli expressed the transgene (Supplementary Figure S2). Thus, PCR screenings with specific primers for wmCENH3-RFP, $Z m C N E H 3-Y F P$ and Bar genes were performed with genomic DNAs from leaves of 182 regenerated wheat plantlets and the predicted sizes of PCR products were $399 \mathrm{bp}$ for $w m \mathrm{CENH} 3-R F P, 474 \mathrm{bp}$ for $Z m C E N H 3-Y F P$ and $452 \mathrm{bp}$ for Bar gene, respectively. Totally 109 transgenic events were identified, including 91 events with Bar gene only (82 events from pCAMBIA3301-wmCENH3-RFP transformation and 9 events from pTF101-ZmCENH3-YFP transformation), 16 events with $w m$ CENH3-RFP (3 events with $w m$ CEHN3-RFP only and 13 events with $w m C E N H 3-R F P+B a r)$ and 2 events with $Z m C E N H 3-Y F P$ (1 event with $Z m C E N H 3-Y F P$ only and 1 event with $Z m C E N H 3-Y F P+B a r)$. Transformation efficiency was $2.69 \%$ for Bar gene, $0.65 \%$ for $w m C E N H 3-R F P$, and $0.13 \%$ for $Z m C E N H 3-Y F P$. More Bar gene was integrated into wheat genome than both alien CNEH3 genes although the Bar gene was located on the same construct with either $w m C E N H 3-R F P$ or $Z m C E N H 3-Y F P$. Transgenic plants were grown in growth chamber and self-pollinated to produce seeds (Figure $3(E)$ ). 


\subsection{Southern Blot and RT-PCR Analysis for Transgenic Wheat}

Southern blot with the DIG-labeled Bar gene was performed in T0 transgenic plants. The results showed $w m$ CENH3-RFP construct was successfully integrated into the genome of T0 transgenic wheat lines of 11-1, C2901, C3057 and C3216. The copy numbers of the transgene were one for 11-1 and C3057 events, two for C2901 event, and four for C3216 event (Figure 4).

To analyze wmCNEH3-RFP gene expression in transgenic wheat, RT-PCR was performed with wild type wheat and transgenic events 11-1, C2901, C3057 and C3216. PCR primers were designed to detect a 399 bp product from the wmCENH3-RFP gene if it was expressed by RT-PCR. A 399 bp wmCENH3-RFP gene product was detected in the four transgenic wheat lines of 11-1, C2901, C3057 and C3216, but no product was detected in the WT wheat (Figure 5(A)).

\subsection{Localization of Ectopically Expressed CENH3}

The expression of fluorescence protein tagged CENH3 proteins were analyzed under a fluorescence microscope in root tips of regenerated transgenic plants. Dotted RFP signals were observed in the nuclei of root tip cells of wmCENH3-RFP transgenic plants (Supplementary Figure S3), suggesting that the wmCENH3-RFP was targeted to functional wheat centromeres. In contrast, fluorescence protein was not observed in the two transgenic plants with the ZmCENH3-YFP gene, being consistent with the previous report by Chen et al. [27]. This evidence indicated the suppression of $Z m C E N H 3$ gene expression in transgenic wheat.

The wmCENH3-RFP fusion protein was further detected by immunostaining with an antibody to the RFP tag at the C-terminus (Figure 5(B)). The expressed wmCENH3-RFP protein was detected in the nucleus of transgenic wheat in a

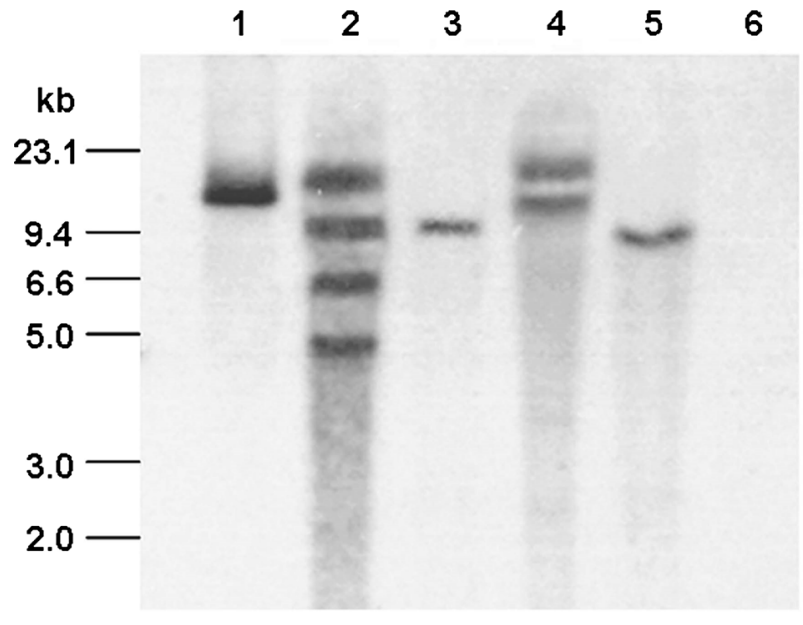

Figure 4. Southern blot of $w m \mathrm{CENH} 3$ transgenic wheat events. Genomic DNAs from T0 transgenic wheat lines C3216 (lane 2), C3057 (lane 3), C2901 (lane 4) and 11-1 (lane 5) were digested with EcoRI. EcoRI-digested pCAMBIA3301 (lane 1) and genomic DNAs from wild type (WT) wheat plants (lane 6) were used as a positive and a negative controls, respectively. The Southern blot was hybridized with digoxygenin (DIG)-labeled probe of the Bar gene. DNA molecular markers were indicated at the left side. 

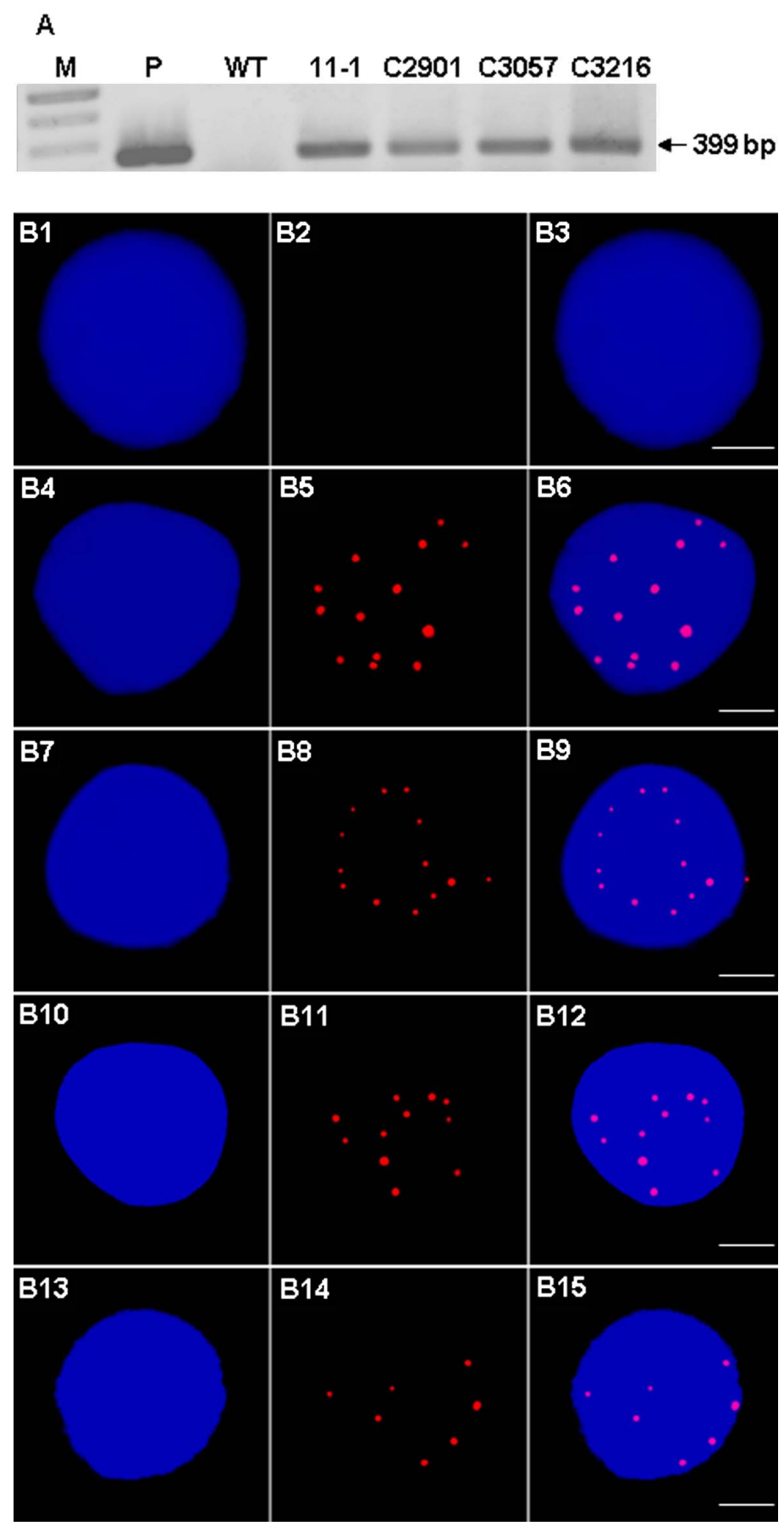

Figure 5. Expression of $w m C E N H 3-R F P$ gene in transgenic wheat. (A) RT-PCR of transgenic wheat events. Lane 1, molecular marker; lane 2, pCAMBIA3301 plasmid DNA as positive control; lane 3 , nontransgenic wheat as negative control; lane 4 - 7, T0 transgenic lines 11-1, C2901, C3057 and C3216. (B) wmCENH3-RFP proteins in the nuclei of transgenic wheat events analyzed by immunostaining. (B1)-(B3), wild type (WT) wheat; (B4)-(B6), transgenic event 11-1; (B7)-(B9), transgenic event C2901; (B10)-(B12), transgenic event C3057; and (B13)-(B15), transgenic event C3216. DAPI-stained nuclei of WT, 11-1, C2901, C3057 and C3216 wheat lines, signals of immunostaining of wmCENH3-RFP proteins in the nuclei and merged images were shown in the left, middle and right panels, respectively. Scale bar $=5 \mu \mathrm{m}$. 
dotted pattern (Figure 5(B)), similar to the centromere localizations detected by direct observation of RFP fluorescence protein tag signals (Supplementary Figure S3).

\subsection{Symmetric Hybridization of Transgenic Wheat and Maize}

Cell suspension cultures for WT wheat and $W m \mathrm{CENH} 3-R F P$ transgenic wheat lines, 11-1, C2901, C3057, and C3216 were established. There was no significant difference in growth performance between WT and four wmCENH3-RFP transgenic wheat cell suspension cultures (Supplementary Figure S4 and Supplementary Figure S5). WT and one of the transgenic line C3216 cultured cells were used for protoplast isolation and somatic hybridization to maize protoplasts.

Spherical protoplasts were isolated from WT and C3216 wheat suspension culture and maize young leaves (Supplementary Figure S6(A) and Figure S6(B)). About equal amount of isolated wheat and maize protoplasts were mixed and cell fusions were induced by PEG. Fused protoplasts were cultured in microplates with P5 medium at a density of $1-5 \times 10^{6}$ protoplasts per $\mathrm{ml}$. The occurrence of hybridization was confirmed by checking the hybridization products with inverted microscope at $1-2 \mathrm{~d}$ after fusion (Supplementary Figure S6(C)). The growth of fused cells at early stage after fusion was observed by an inverted microscope (Supplementary Figure S6(D)).

\subsection{Cytological Examinations of Somatic Hybrids}

Aceto-orcein staining analysis was performed to investigate chromosome behaviors during mitosis in somatic hybrids. Abnormal chromosomes behaviors such as micronuclear, asynchronous nucleus formation, lagging chromatin or chromosomes were observed in somatic hybrids from non-transgenic wheat/ $Z m C E N H 3-Y F P$ transgenic maize and wmCENH3-RFP transgenic wheat $/ Z m C E N H 3-Y F P$ transgenic maize, respectively (Figure 6). In somatic hybrids of both hybridizations, micronuclear formation could be observed frequently in both single cells and dividing cells. Micronuclei occurred during the whole process of mitosis, including interphase (Figure 6(A1) and Figure 6(B1)), telophase, and cytokinesis (Figures 6(A3)-(A5) and Figures 6(B2)-(B4)). Lagging chromosomes occurred at anaphase or lagging chromatin in the cleavage furrow (Figure 6(A5) and Figure 6(B5)), asynchronous nucleus formation as loose chromatin and condensed chromatin (Figure 6(A6)), asynchronous cell cycle as metaphase and interphase occurred simultaneously (Figure 6(B5)) in the dividing cell, and also asynchronous mitosis (Figure 6(A2) and Figure 6(B2)). These results demonstrated that frequently abnormal chromosome behaviors might occur at early stage of somatic hybrid development and the synthetic wmCENH3 could not eliminate the abnormal chromosome behaviors in the somatic hybrid cells.

A FISH analysis was performed in somatic hybrid cells with maize CentC and B-repeat probes to detect maize and wheat chromosomes, respectively. Maize CentC probe specifically hybridized to the centromere regions of maize chromosomes 

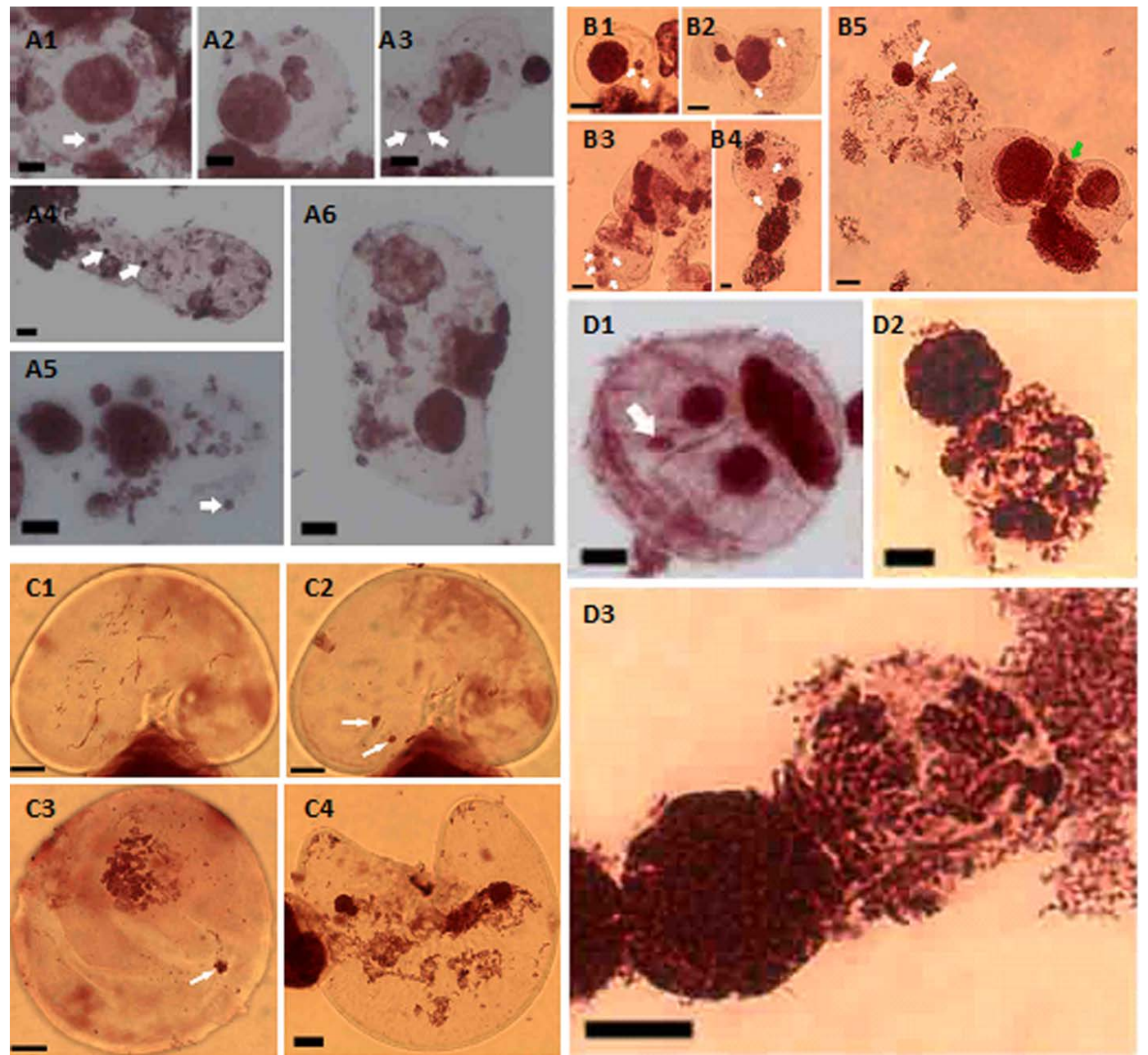

Figure 6. Cytological analyses of somatic hybrids by Aceto-orcein staining. (A1)-(A6) Micronuclei (white arrows showed in (A1), (A3), (A4), and (A5)) and asynchronous nucleus formation ((A2), and (A6)) observed in the somatic hybrid of non-transgenic wheat $\times$ ZmCENH3YFP maize mesophyll protoplast. (B1)-(B5) Micronuclei (white arrows showed in B1-B4), asynchronous nucleus formation (white arrows showed in (B5)), and lagging chromatin (green arrow showed in (B5)) observed in the somatic hybrid of non-transgenic wheat $\times$ maize mesophyll protoplasts. (C1)-(C4) Micronuclei (white arrows showed in the same cell C1 and C2 at different focus levels) and also in (C3), and asynchronous nucleus formation (C4) observed in the fusion protoplasts of transgenic wheat C3057 and ZmCENH3YFP maize mesophyll. (D1)-(D3) Micronuclei (white arrows showed in D1) and asynchronous nucleus formation ((D2) and (D3)) observed in the fusion protoplasts of transgenic wheat C3216 and maize mesophyll protoplasts. Scale bars = $10 \mu \mathrm{m}$.

[42]. The maize B-repeat probe that hybridizes specifically to maize B chromosomes was found to hybridize strongly to the sub-telomere regions of wheat chromosomes (Supplementary Figure S1). Thus, a mixture of maize CentC and B repeat probes was used to distinguish wheat and maize chromosomes in somatic hybrids of wheat/maize and to investigate the chromosome components in somatic hybrids. In the dividing cells of both non-transgenic and transgenic wheat/maize somatic hybrids, maize chromosome components could only be detected in newly fused cells or unfused maize cells (Figure 7(C) and Figure 7(D)), but 


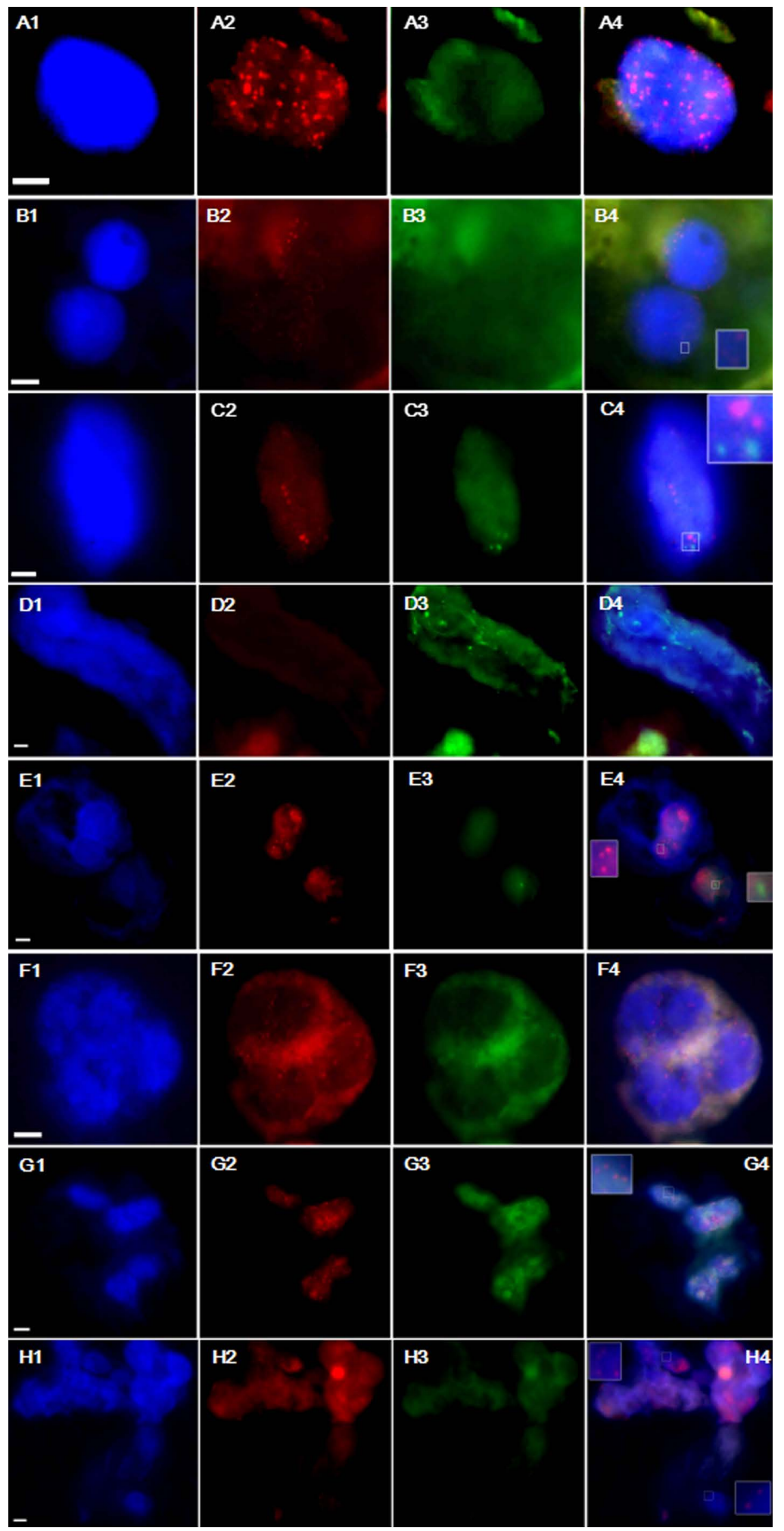

Figure 7. FISH analysis of wheat $\times$ maize somatic hybrids. (A)-(B) dividing cells in somatic hybrids of non-transgenic wheat $\times$ ZmCENH3-YFP maize mesophyll protoplast. (C)-(H) dividing cells in somatic hybrids of transgenic wheat C3216 $\times$ ZmCENH3-YFP maize mesophyll protoplast. (C) newly fused cells, (D) unfused maize cells, (E) somatic hybrid cells at second cell division, (F)-(H) multiple cell clusters. Scale bars $=5 \mu \mathrm{m}$. 
could not be detected in the divided cells and microcell clusters (Figure 7(A), Figure 7(B), Figure 7(F), Figure 7(G) \& Figure $7(\mathrm{H})$ ). The elimination of maize chromosomes was observed in the second cell division of somatic hybrids (Figure 7(E)).

\subsection{CENH3 Behavior in Somatic Hybrids}

The wmCNEH3 and ZmCENH3 proteins in somatic hybrid cells were investigated by immunostaining analysis during $11-14 \mathrm{~d}$ after fusion. Both RFP and YFP signals were observed in the nuclei of somatic hybrid cells as diffused patterns (Figure 8), which was different from the dotted pattern observed before protoplast fusion (Figure 5(B) and Supplementary Figure S7). Fragments of chromatin were observed near the cell plate at anaphase of cell division, while the majority had moved to the polar regions. The loss of chromatin fragments was also reported in other somatic hybridization systems, which were considered as lost chromosome fragments [25] [46].

\section{Discussions}

\subsection{Fragmentation of Transformed DNAs}

Genetic transformation by particle bombardment usually produces complex transgene loci with multiple copies, truncated, rearranged sequences interspersed with genomic DNA fragments [47] [48]. In this research, we observed only 14 out of 109 transgenic wheat plants (12.84\%) that had full length DNA fragments, and most of the transgenic events had fragmented transgenes, indicating the
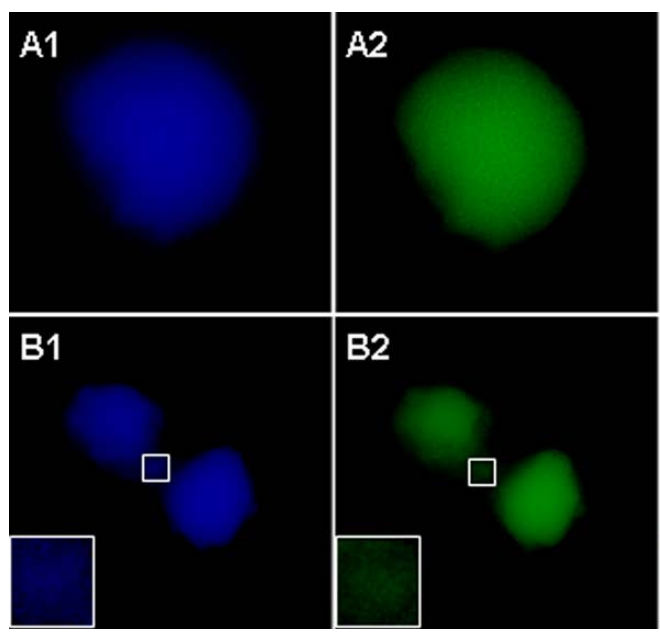
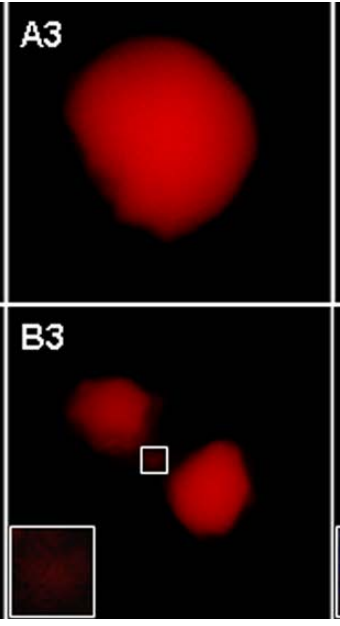
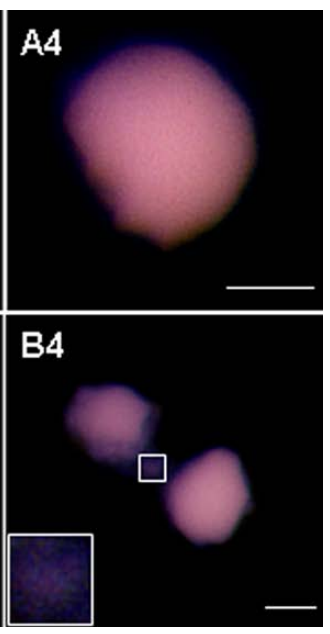

Figure 8. Detection of CENH3 behavior in somatic hybrid cells of wmCENH3-RFP transgenic wheat $\times$ ZmCENH3-YFP transgenic maize. wmCENH3-RFP and ZmCENH3-YFP proteins in the nuclei of somatic hybrids were immunostained with a rabbit-derive primary antibody to the red fluorescence protein (RFP) and a mouse-derived primary antibody to the yellow fluorescence protein (YFP), respectively, and detected by anti-rabbit rhodamine and FITC conjugated anti-mouse secondary antibodies. Nuclei from an interphase cell ((A1)-(A4)) and a telophase cell ((B1)-(B4)) were presented as DAPI stained nuclei ((A1) and (B1)), ZmCENH3 ((A2) and (B2)), wmCENH3 ((A3) and (B3)), and merged images ((A4) and (B4)). Inlets show chromatin loss at cell divisions ((B1)-(B4)). Scale bars $=5 \mu \mathrm{m}$. 
fragmentation and rearrangement of transformed DNAs. The high frequent fragmentation of transgenes and nonrandomized transformation could be mainly caused by the following factors. First, plasmid DNAs might be vulnerable to shearing during gold particle coating. Plasmid DNAs were coated to golden particles in biolistic transformation. The frequent vortexing, precipitation and centrifugation during coating may mechanically shear the plasmid DNA and produce fragmented DNAs before transformation. Second, high velocity particle bombardment could be another factor to produce DNA fragmentation. Highspeed gold particles during bombardment could create double strand breaks (DSBs) on genomic DNA that initiate the transgene integration, and at the same time, they could also create fragmentation of delivered DNAs on gold particle. Third, foreign DNA integration into the genome is an enzymatic reaction. Foreign DNAs are integrated as DSBs by endogenous DNA repair system, which relies mainly on the non-homologous end joining (NHEJ) system in plants. The binding of DSBs by KU70 - KU80 complex protects the broken DNA ends from degradation by exonuclease, but allows DNA end processing factors to modify the DSBs to produce DNA ends suitable for ligation by the DNA ligases [49]. Major or minor chromosome rearrangements could occur to separate or change the position of alien DNA elements [32] [47]. Southern blot and FISH analysis of transgene loci in transgenic hexaploid oat revealed that transgene integration was associated with chromosomal breakage and rearrangements [50], and more complex transgene integration loci and configuration could be induced through the minor rearrangements and undesirable plasmids backbone vector.

\subsection{Biased Transformation and Recovery of Transgenic Wheat with CENH3 Transgenes}

In this study we observed significantly more transgenic events with Bar gene only $(83.5 \%)$ than those with either $Z m C E N H 3$ or $w m C E N H 3$ genes $(16.5 \%)$, although the Bar gene was on the same constructs. The bias against CENH3 transgene indicates that the transformation might be not random. Two reasons may contribute to the biased transformation. First, transgenic plants were selected on culture medium supplemented with Bialaphos, which is an herbicide that can be detoxified by phosphinothricin acetyltransferase encoded by the Bar gene. This selection would not allow the growth and regeneration of transgenic events without a functional Bargene expression system, and thus kill most of the transgenic plants with ZmCENH3 or wmCENH3 only. However, the short selection on this medium during the genetic transformation would allow a few transgenic plants without the Bar gene to escape the selection, and thus one plant with the ZmCENH3 gene only and 3 plants with the wmCENH3 gene only were recovered. In addition, there might be a competition between endogenous CENH3 and the ectopically expressed ones, which might be toxic or malfunctional when deposited in the centromeres. Two transgenic events (C1479 and \#52) were identified when maize full length CENH3 gene tagged with YFP was transformed to 
wheat callus by PCR in T0 generation. But no YFP signals were observed in the root tips of these two events under fluorescence microscope. Similar results have been reported by Chen et al. [27], who observed the competition and suppression of $Z m C E N H 3$ transcription by endogenous wheat TaCENH3. The transgenic $Z m C E N H 3$ can be weakly transcribed and the ZmCENH3-YFP protein is not observed by both western and immunostaining analyses, whereas the expression of endogenous TaCENH3 is up-regulated in transgenic wheat [27]. In contrast, we observed higher transformation efficiency with the synthetic wmCENH3 gene $(0.65 \%)$ than the $Z m C E N H 3$ construct $(0.13 \%)$, and the expression of wmCENH3 was successful in transgenic wheat.

The difference between the two transgenes is the overall sequence similarity to wheat $\mathrm{TaCENH} 3$ and the $\mathrm{N}$-terminal part of CENH3 proteins that is highly variable and critical for kinetichore assembly. In Arabidopsis, the N-terminal part of AtCENH3 is required for its loading to centromeres during meiosis and mitosis [51], and the divergence of the $\mathrm{N}$-terminal tail could cause chromosome missegregation and genome elimination in hybrids between wild type plants and engineered Arabidopsis that expressed a chimeric CENH3 [3]. In addition, high sequence similarity to endogenous $\mathrm{CENH} 3$ protein has been reported to be required for heterologeous CENH3 recognition in A. thaliana centromeres [51], although there are other reports wherein the highly diverged maize $\mathrm{ZmCENH3}$ localized in A. thaliana [3] [52]. The missegregation and chromosome elimination are positively related to the degree of CENH3 divergence. Crosses between wild type and Arabidopsis cenh3 mutants that express the maize ZmCENH3 can produce more missegregation and haploids than those crosses with Arabidopsis cenh3 mutants that express CENH3 from a closely related $L$. oleraceum species [52]. Alignment of maize and wheat CENH3s demonstrates that the full length proteins are $74 \%$ similarity. The similarities are $60 \%$ in the N-terminal part before Loop 1 and $92 \%$ in the C-terminal part after Loop 1, respectively. The domain swap between wheat TaCENH3 and maize $\mathrm{ZmCENH3}$ resulted in a fusion protein with the $\mathrm{N}$-terminal tail from $\mathrm{TaCENH} 3$, and the overall protein similarity between the synthetic wmCENH3 and wheat TaCENH3 was increased to 95\% (Figure 2(A)). The relatively low frequency in obtaining transgenic wheat with the full length maize $Z m C E N H 3$ gene may suggest that transgenic plant with this transgene might have detrimental effect on the growth and development of transgenic events. We argue that the suppression of $Z m C E N H 3$ gene expression observed by us and Chen et al. [27] could in part reduce the detrimental effects on transgenic wheat, which can be ameliorated by the chimeric CENH3 with a wheat $\mathrm{N}$-terminal tail, and the increased sequence similarity to wheat CENH3. Thus, the higher transformation efficiency with the synthetic $w m C E N H 3$ gene than the $Z m C E N H 3$ construct, and the successful expression and localization of wmCENH3 might be attributed to less competition between endogenous CENH3 and the ectopically expressed ones in transgenic wheat, although the endogenous TaCENH3 expression was not determined in this re- 
search.

\subsection{Ectopically Expressed wmCENH3 in Wheat/Maize Somatic Hybridization}

Abnormal chromosome behaviors were observed frequently in the somatic hybrids, indicating the occurrence of chromosome elimination. Cytological studies of these somatic hybrids revealed various abnormal chromosome behaviors such as micronuclei, asynchronous cell cycle, and chromosome lagging (Figure 6). Previous studies demonstrate that maize chromosomes without spindle microtubule attachment are stayed or delayed in the metaphase plate during first mitosis of zygotic hybrids of wheat/maize [26], and maize chromosomes could be gradually eliminated from the hybrids in several cell cycles [24]

Many evidences show that chromosome elimination is related to the loss or malfunction of CENH3 [2] [3] [4] [5] [52]. By analyzing CENH3 behavior in early somatic hybrids between transgenic wheat with a synthetic wmCENH3-RFP and transgenic maize with the ZmCENH3-YFP, we could detect the change of the CENH3 localization patterns from the normally dotted centromere localization to a diffused pattern in the whole nuclear chromatins (Figure 8).

Eukaryotic chromosomes can have three types of centromeres including point centromeres, monocentromeres and holocentromeres [53]. As a centromere marker, $\mathrm{CNEH} 3$ protein is mainly deposited to the active centromeres, and its distribution can vary depending on the type of centromeres. CENH3 on monocentric or point centromeres is usually observed as dotted patterns. In contrast, CENH3 is almost evenly distributed on the whole holocentric chromosomes. Wheat and maize have monocentric chromosomes and thus their CENH3 localization usually displays a dotted pattern in the nuclei. The heterogeneous expression of wmCENH3-RFP in wheat also displayed a dotted pattern (Figure 5(B)), indicating that this heterogeneous CENH3 might be incorporated into wheat centromeres. Similar results have also been reported in heterogeneous expressions of CENH3s from A. lyrata, A. arenosa, Capsella bursa-pastoris, Zea mays, Nicotiana tabacum, and L. oleraceum in A. thaliana [3] [51] [52] [54], as well as $A$. thaliana AtCENH3 in tobacco BY-2 cells [54]. Our observation of mislocalization of both ZmCENH3-YFP and wmCENH3-RFP in wheat/maize somatic hybrids may suggest a mechanism of centromere inactivation in somatic hybrids, which could be responsible for chromosome elimination partially.

\section{Acknowledgements}

We thank Dr. James Birchler (University of Missouri-Columbia) for providing the construct of pTF101-ZmCNEH-YFP and the seeds of ZmCENH3-YFP maize, Dr. Eliezer S. Louzada (Texas A\&M University-Kingsville) for assistance in somatic hybridization. This work was supported by China Postdoctoral Science Foundation (2017M612741), Natural Science Foundation of Guangdong Province (2018A030310446), Guangdong Innovation Research Team Fund (2014ZT05S078) 
and Research Grants Council (RGC) of Hong Kong (480209).

\section{Author Contribution}

X.Y, J.L, and W.Y designed the experiment and wrote the manuscript. X.Y and J.L performed the experiments.

\section{Conflicts of Interest}

The authors declare no conflicts of interest regarding the publication of this paper.

\section{References}

[1] Bloom, K. (2007) Centromere Dynamics. Current Opinion in Genetics \& Development, 17, 151-156. https://doi.org/10.1016/j.gde.2007.02.009

[2] Ravi, M. and Chan, S.W.L. (2010) Haploid Plants Produced by Centromere-Mediated Genome Elimination. Nature, 464, 615-618.

https://doi.org/10.1038/nature08842

[3] Maheshwari, S., Tan, E.H., West, A., Franklin, F.C., Comai, L. and Chan, S.W. (2015) Naturally Occurring Differences in CENH3 Affect Chromosome Segregation in Zygotic Mitosis of Hybrids. PLOS Genetics, 11, e1004970. https://doi.org/10.1371/journal.pgen.1004970

[4] Sanei, M., Pickering, R., Kumke, K., Nasuda, S. and Houben, A. (2011) Loss of Centromeric Histone H3 (CENH3) from Centromeres Precedes Uniparental Chromosome Elimination in Interspecific Barley Hybrids. Proceedings of the National Academy of Sciences, 108, E498-E505. https://doi.org/10.1073/pnas.1103190108

[5] Jin, W., Melo, J.R., Nagaki, K., Talbert, P.B., Henikoff, S., Dawe, R.K. and Jiang, J. (2004) Maize Centromeres: Organization and Functional Adaptation in the Genetic Background of Oat. Plant Cell, 16, 571-581. https://doi.org/10.1105/tpc.018937

[6] Malik, H.S. and Henikoff, S. (2002) Conflict Begets Complexity: The Evolution of Centromeres. Current Opinion in Genetics \& Development, 12, 711-718. https://doi.org/10.1016/S0959-437X(02)00351-9

[7] Talbert, P.B., Masuelli, R., Tyagi, A.P., Comai, L. and Henikoff, S. (2002) Centromeric Localization and Adaptive Evolution of an Arabidopsis Histone H3 Variant. Plant Cell, 14, 1053-1066. https://doi.org/10.1105/tpc.010425

[8] Rieseberg, L.H. and Carney, S.E. (1998) Plant Hybridization. New Phytologist, 140, 599-624. https://doi.org/10.1046/j.1469-8137.1998.00315.x

[9] Brock, M. (2009) Prezygotic Barriers to Gene Flow between Taraxacum ceratophorum and the Invasive Taraxacum officinale (Asteraceae). Oecologia, 161, 241-251. https://doi.org/10.1007/s00442-009-1383-0

[10] Schiestl, F.P. and Schlüter, P.M. (2009) Floral Isolation, Specialized Pollination, and Pollinator Behavior in Orchids. Annual Review of Entomology, 54, 425-446. https://doi.org/10.1146/annurev.ento.54.110807.090603

[11] Swanson, R., Edlund, A.F. and Preuss, D. (2004) Species Specificity in Pollen-Pistil Interactions. Annual Review of Genetics, 38, 793-818.

https://doi.org/10.1146/annurev.genet.38.072902.092356

[12] Kranz, E. and Scholten, S. (2008) In Vitro Fertilization: Analysis of Early Post-Fertilization Development Using Cytological and Molecular Techniques. Sexual Plant 
Reproduction, 21, 67-77. https://doi.org/10.1007/s00497-007-0060-x

[13] Stebbins, G.L. and Demerec, M. (1958) The Inviability, Weakness, and Sterility of Interspecific Hybrids. Advances in Genetics, 9, 147-215. https://doi.org/10.1016/S0065-2660(08)60162-5

[14] Wu, C.I. (1992) A Note on Haldane's Rule: Hybrid Inviability versus Hybrid Sterility. Evolution, 46, 1584-1587. https://doi.org/10.1111/j.1558-5646.1992.tb01152.x

[15] Johansen-Morris, A.D. and Latta, R.G. (2006) Fitness Consequences of Hybridization between Ecotypes of Avena barbata: Hybrid Breakdown, Hybrid Vigor, and Transgressive Segregation. Evolution, 60, 1585-1595. https://doi.org/10.1111/j.0014-3820.2006.tb00503.x

[16] Bomblies, K. and Weigel, D. (2007) Hybrid Necrosis: Autoimmunity as a Potential Gene-Flow Barrier in Plant Species. Nature Reviews Genetics, 8, 382-393. https://doi.org/10.1038/nrg2082

[17] Gernand, D., Rutten, T., Varshney, A., Rubtsova, M., Prodanovic, S., Bruss, C., Kumlehn, J., Matzk, F. and Houben, A. (2005) Uniparental Chromosome Elimination at Mitosis and Interphase in Wheat and Pearl Millet Crosses Involves Micronucleus Formation, Progressive Heterochromatinization, and DNA Fragmentation. Plant Cell, 17, 2431-2438. https://doi.org/10.1105/tpc.105.034249

[18] Gernand, D., Rutten, T., Pickering, R. and Houben, A. (2006) Elimination of Chromosomes in Hordeum vulgare $\times H$. bulbosum Crosses at Mitosis and Interphase Involves Micronucleus Formation and Progressive Heterochromatinization. Cytogenetic and Genome Research, 114, 169-174. https://doi.org/10.1159/000093334

[19] Baum, M., Lagudah, E.S. and Appels, R. (1992) Wide Crosses in Cereals. Annual Review of Plant Physiology and Plant Molecular Biology, 43, 117-143. https://doi.org/10.1146/annurev.pp.43.060192.001001

[20] Sharma, D.R., Kaur, R. and Kumar, K. (1996) Embryo Rescue in Plants-A Review. Euphytica, 89, 325-337.

[21] Barclay, I.R. (1975) High Frequencies of Haploid Production in Wheat (Triticum aestivum) by Chromosome Elimination. Nature, 256, 410-411. https://doi.org/10.1038/256410a0

[22] Laurie, D.A. and Bennett, M.D. (1986) Wheat $\times$ Maize Hybridization. Canadian Journal of Genetics and Cytology, 28, 313-316. https://doi.org/10.1139/g86-046

[23] Laurie, D.A. and Bennett, M.D. (1988) The Production of Haploid Wheat Plants from Wheat $\times$ Maize Crosses. Theoretical and Applied Genetics, 76, 393-397. https://doi.org/10.1007/BF00265339

[24] Laurie, D.A. and Bennett, M.D. (1989) The Timing of Chromosome Elimination in Hexaploid Wheat $\times$ Maize Crosses. Genome, 32, 953-961.

https://doi.org/10.1139/g89-537

[25] Xu, C., Xia, G., Zhi, D., Xiang, F. and Chen, H. (2003) Integration of Maize Nuclear and Mitochondrial DNA into the Wheat Genome through Somatic Hybridization. Plant Science, 165, 1001-1008. https://doi.org/10.1016/S0168-9452(03)00287-5

[26] Mochida, K., Tsujimoto, H. and Sasakuma, T. (2004) Confocal Analysis of Chromosome Behavior in Wheat $\times$ Maize Zygotes. Genome, 47, 199-205.

https://doi.org/10.1139/g03-123

[27] Chen, W., Zhu, Q., Wang, H., Xiao, J., Xing, L., Chen, P., Jin, W. and Wang, X.E. (2015) Competitive Expression of Endogenous Wheat CENH3 May Lead to Suppression of Alien ZmCENH3 in Transgenic Wheat $\times$ Maize Hybrids. Journal of 
Genetics and Genomic, 42, 639-649. https://doi.org/10.1016/j.jgg.2015.05.006

[28] Christensen, A.H. and Quail, P.H. (1996) Ubiquitin Promoter-Based Vectors for High-Level Expression of Selectable and/or Screenable Marker Genes in Monocotyledonous Plants. Transgenic Research, 5, 213-218. https://doi.org/10.1007/BF01969712

[29] Redway, F.A., Vasil, V., Lu, D. and Vasil, I.K. (1990) Identification of Callus Types for Long-Term Maintenance and Regeneration from Commercial Cultivars of Wheat (Triticum aestivum L.). Theoretical and Applied Genetics, 79, 609-617. https://doi.org/10.1007/BF00226873

[30] Jefferson, R.A., Kavanagh, T.A. and Bevan, M.W. (1987) GUS Fusions: Beta-Glucuronidase as a Sensitive and Versatile Gene Fusion Marker in Higher Plants. The EMBO Journal, 6, 3901. https://doi.org/10.1002/j.1460-2075.1987.tb02730.x

[31] Bimboim, H.C. and Doly, J. (1979) A Rapid Alkaline Extraction Procedure for Screening Recombinant Plasmid DNA. Nucleic Acids Research, 7, 1513-1523. https://doi.org/10.1093/nar/7.6.1513

[32] Altpeter, F., Vasil, V., Srivastava, V., Stöger, E. and Vasil, I.K. (1996) Accelerated Production of Transgenic Wheat (Triticum aestivum L.) Plants. Plant Cell Reports, 16, 12-17. https://doi.org/10.1007/BF01275440

[33] Vasil, I.K. and Vasil, V. (2006) Transformation of Wheat via Particle Bombardment. Methods in Molecular Biology, 318, 273. https://doi.org/10.1385/1-59259-959-1:273

[34] Edwards, K., Johnstone, C. and Thompson, C. (1991) A Simple and Rapid Method for the Preparation of Plant Genomic DNA for PCR Analysis. Nucleic Acids Research, 19, 1349. https://doi.org/10.1093/nar/19.6.1349

[35] Kanai, R. and Edwards, G.E. (1973) Separation of Mesophyll Protoplasts and Bundle Sheath Cells from Maize Leaves for Photosynthetic Studies. Plant Physiology, 51, 1133-1137. https://doi.org/10.1104/pp.51.6.1133

[36] Armstrong, C.L., Petersen, W.L., Buchholz, W.G., Bowen, B.A. and Sulc, S.L. (1990) Factors Affecting PEG-Mediated Stable Transformation of Maize Protoplasts. Plant Cell Reports, 9, 335-339. https://doi.org/10.1007/BF00232864

[37] Xia, G. and Chen, H. (1996) Plant Regeneration from Intergeneric Somatic Hybridization between Triticum aestivum L. and Leymus chinensis (Trin.) Tzvel. Plant Science, 120, 197-203. https://doi.org/10.1016/S0168-9452(96)04492-5

[38] Grosser, J., Calović, M. and Louzada, E. (2010) Protoplast Fusion Technology-Somatic Hybridization and Cybridization. In: Plant Cell Culture, John Wiley \& Sons, Hoboken, 175-198. https://doi.org/10.1002/9780470686522.ch10

[39] Ross, K., Fransz, P. and Jones, G. (1996) A Light Microscopic Atlas of Meiosis in Arabidopsis thaliana. Chromosome Research, 4, 507-516. https://doi.org/10.1007/BF02261778

[40] Storey, W.B. and Mann, J.D. (1967) Chromosome Contraction by O-Isopropyl-NPhenylcarbamate (IPC). Biotechnic \& Histochemistry, 42, 15-18. https://doi.org/10.3109/10520296709114976

[41] Alfenito, M.R. and Birchler, J.A. (1993) Molecular Characterization of a Maize B Chromosome Centric Sequence. Genetics, 135, 589-597.

[42] Ananiev, E.V., Phillips, R.L. and Rines, H.W. (1998) Chromosome-Specific Molecular Organization of Maize (Zea mays L.) Centromeric Regions. Proceedings of the National Academy of Sciences, 95, 13073-13078.

https://doi.org/10.1073/pnas.95.22.13073 
[43] Wiegant, J., Verwoerd, N., Mascheretti, S., Bolk, M., Tanke, H.J. and Raap, A.K. (1996) An Evaluation of a New Series of Fluorescent dUTPs for Fluorescence in Situ Hybridization. Journal of Histochemistry \& Cytochemistry, 44, 525-529. https://doi.org/10.1177/44.5.8627009

[44] Kato, A., Lamb, J.C. and Birchler, J.A. (2004) Chromosome Painting Using Repetitive DNA Sequences as Probes for Somatic Chromosome Identification in Maize. Proceedings of the National Academy of Sciences, 101, 13554-13559. https://doi.org/10.1073/pnas.0403659101

[45] Kato, A. (1999) Air Drying Method Using Nitrous Oxide for Chromosome Counting in Maize. Biotechnic \& Histochemistry, 74, 160-166. https://doi.org/10.3109/10520299909047968

[46] Cui, H., Sun, Y., Deng, J., Wang, M. and Xia, G. (2015) Chromosome Elimination and Introgression Following Somatic Hybridization between Bread Wheat and Other Grass Species. Plant Cell, Tissue and Organ Culture, 120, 203-210. https://doi.org/10.1007/s11240-014-0594-1

[47] Kohli, A., Leech, M., Vain, P., Laurie, D.A. and Christou, P. (1998) Transgene Organization in Rice Engineered through Direct DNA Transfer Supports a Two-Phase Integration Mechanism Mediated by the Establishment of Integration Hot Spots. Proceedings of the National Academy of Sciences, 95, 7203-7208. https://doi.org/10.1073/pnas.95.12.7203

[48] Pawlowski, W.P. and Somers, D.A. (1998) Transgenic DNA Integrated into the Oat Genome Is Frequently Interspersed by Host DNA. Proceedings of the National Academy of Sciences, 95, 12106-12110. https://doi.org/10.1073/pnas.95.21.12106

[49] Waterworth, W.M., Drury, G.E., Bray, C.M. and West, C.E. (2011) Repairing Breaks in the Plant Genome: The Importance of Keeping It Together. New Phytologist, 192, 805-822. https://doi.org/10.1111/j.1469-8137.2011.03926.x

[50] Svitashev, S., Ananiev, E., Pawlowski, W.P. and Somers, D.A. (2000) Association of Transgene Integration Sites with Chromosome Rearrangements in Hexaploid Oat. Theoretical and Applied Genetics, 100, 872-880. https://doi.org/10.1007/s001220051364

[51] Moraes, I., Lermontova, I. and Schubert, I. (2011) Recognition of $A$. thaliana Centromeres by Heterologous CENH3 Requires High Similarity to the Endogenous Protein. Plant Molecular Biology, 75, 253-261. https://doi.org/10.1007/s11103-010-9723-3

[52] Maheshwari, S., Ishii, T., Brown, C.T., Houben, A. and Comai, L. (2017) Centromere Location in Arabidopsis Is Unaltered by Extreme Divergence in CENH3 Protein Sequence. Genome Research, 27, 471-478. https://doi.org/10.1101/gr.214619.116

[53] Heckmann, S., Macas, J., Kumke, K., Fuchs, J., Schubert, V., Ma, L., Novak, P., Neumann, P., Taudien, S., Platzer, M. and Houben, A. (2012) The Holocentric Species Luzula elegans Shows Interplay between Centromere and Large-Scale Genome Organization. The Plant Journal, 73, 555-565. https://doi.org/10.1111/tpj.12054

[54] Nagaki, K., Terada, K., Wakimoto, M., Kashihara, K. and Murata, M. (2010) Centromere Targeting of Alien CENH3s in Arabidopsis and Tobacco Cells. Chromosome Research, 18, 203-211. https://doi.org/10.1007/s10577-009-9108-0 


\section{Supplementary Figures}
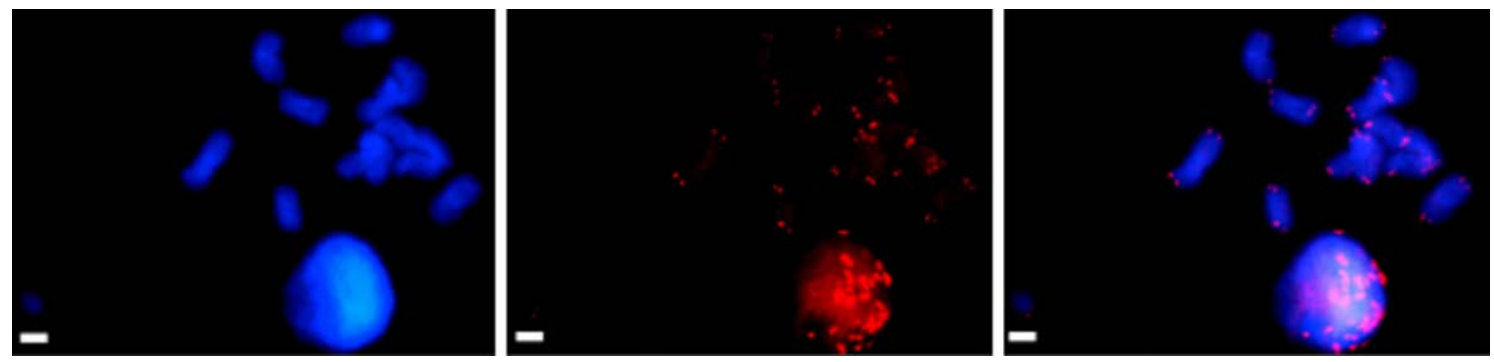

Figure S1. FISH analysis of the maize B-repeat to chromosomes of an aneuploid wheat cell line. Maize B-repeat probe was labeled with Chroma Tide Alexa Fluor 594-5-dUTP (Invitrogen). White arrows point to hybridization signals in subtelomere regions of wheat chromosomes. Scale bars $=5 \mu \mathrm{m}$.

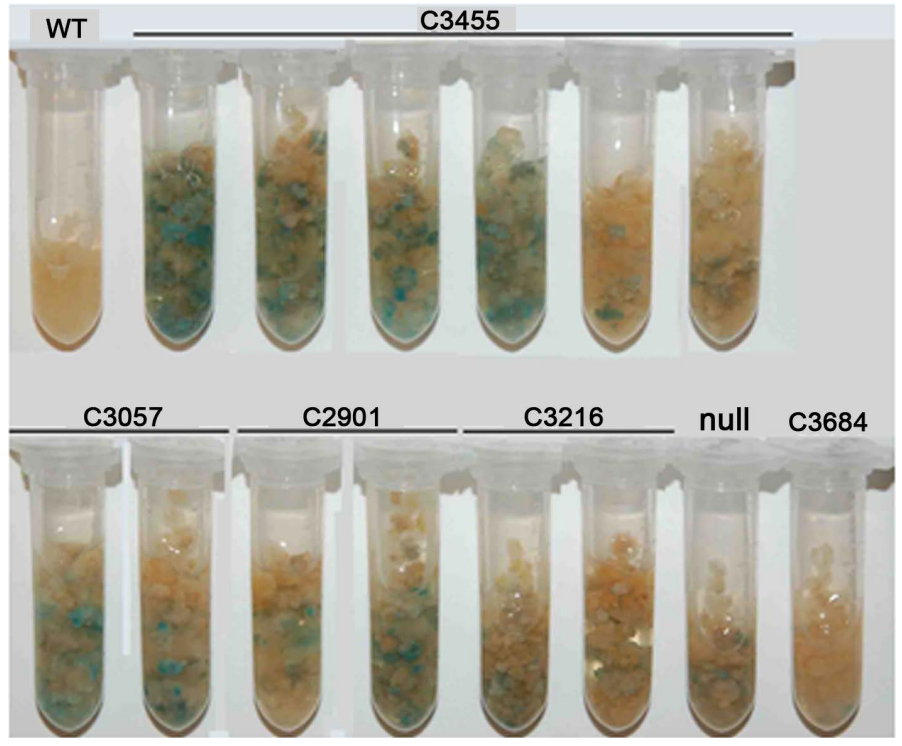

Figure S2. GUS staining of wild type (WT) and T0 generation transgenic wheat calli. Six transgenic events (C3455, C3057, C2901, C3216, null and C3684) were shown to have different proportions of cells were transformed. Scale bars $=0.5 \mathrm{~cm}$.
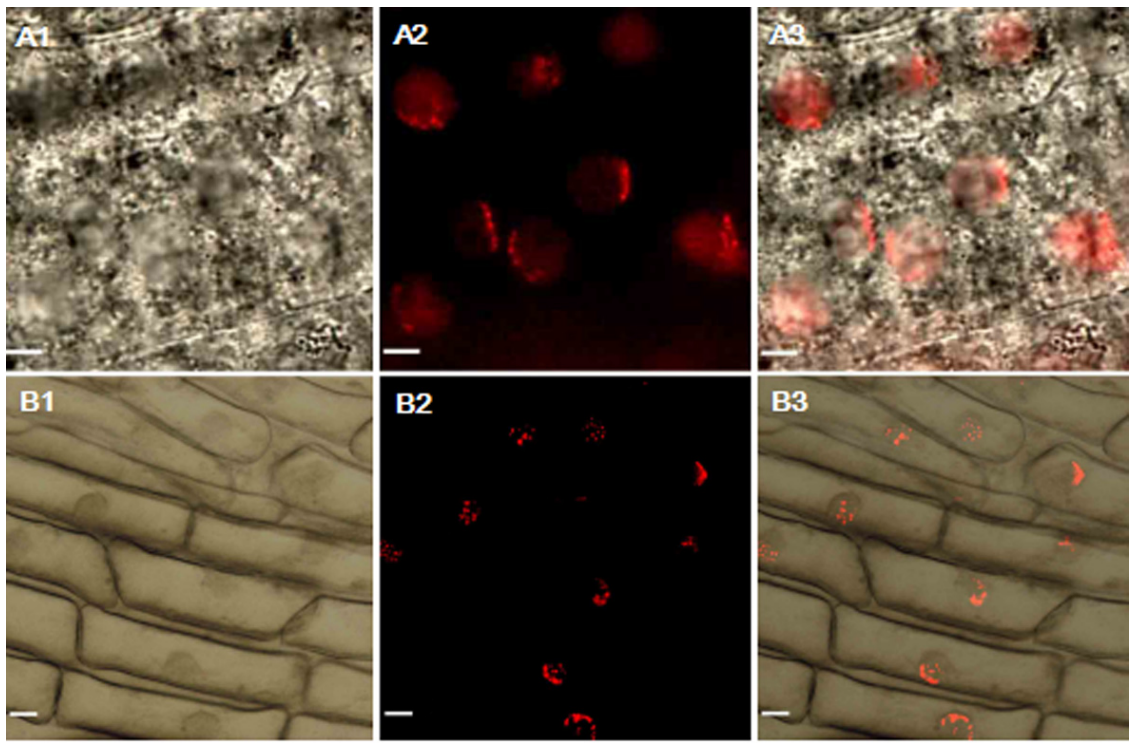


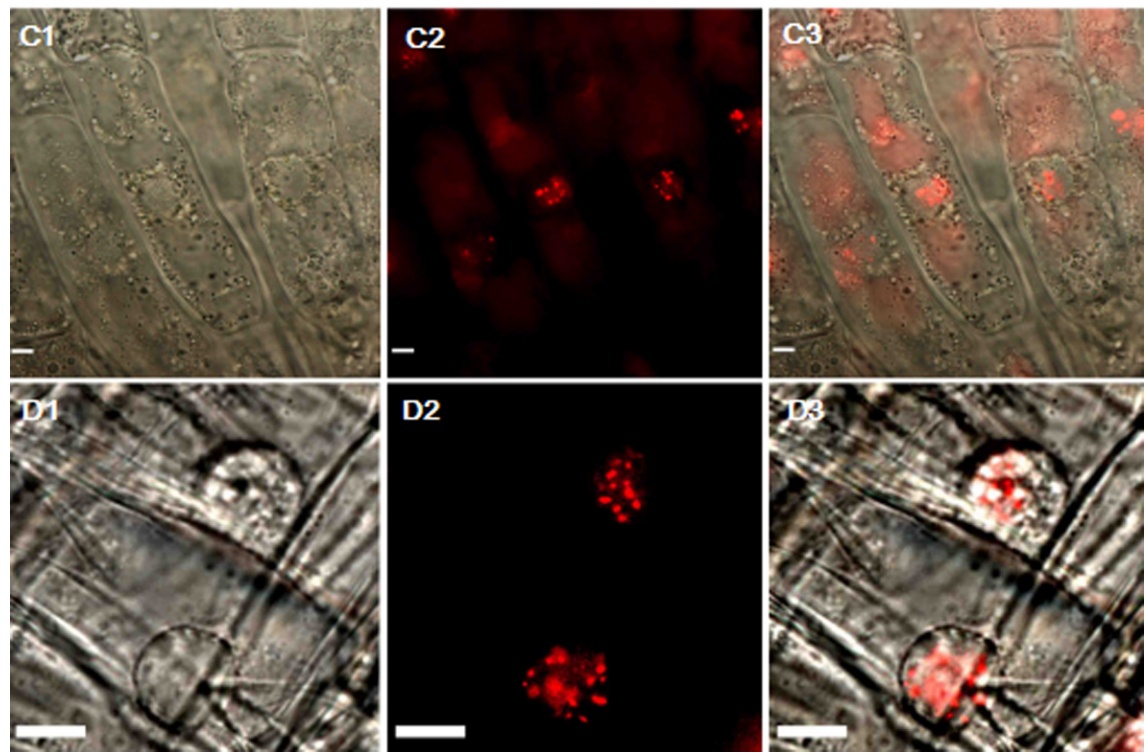

Figure S3. RFP signals in root tips of transgenic wheat plants. (A) T0 generation of transgenic wheat plant C3541; (B) (C) T1 generation of transgenic wheat plant C3541; (D) T0 generation of transgenic wheat plant \#43. Scale bars $=5 \mu \mathrm{m}$ in (A), (C), and (D), $10 \mu \mathrm{m}$ in $(\mathrm{B})$.

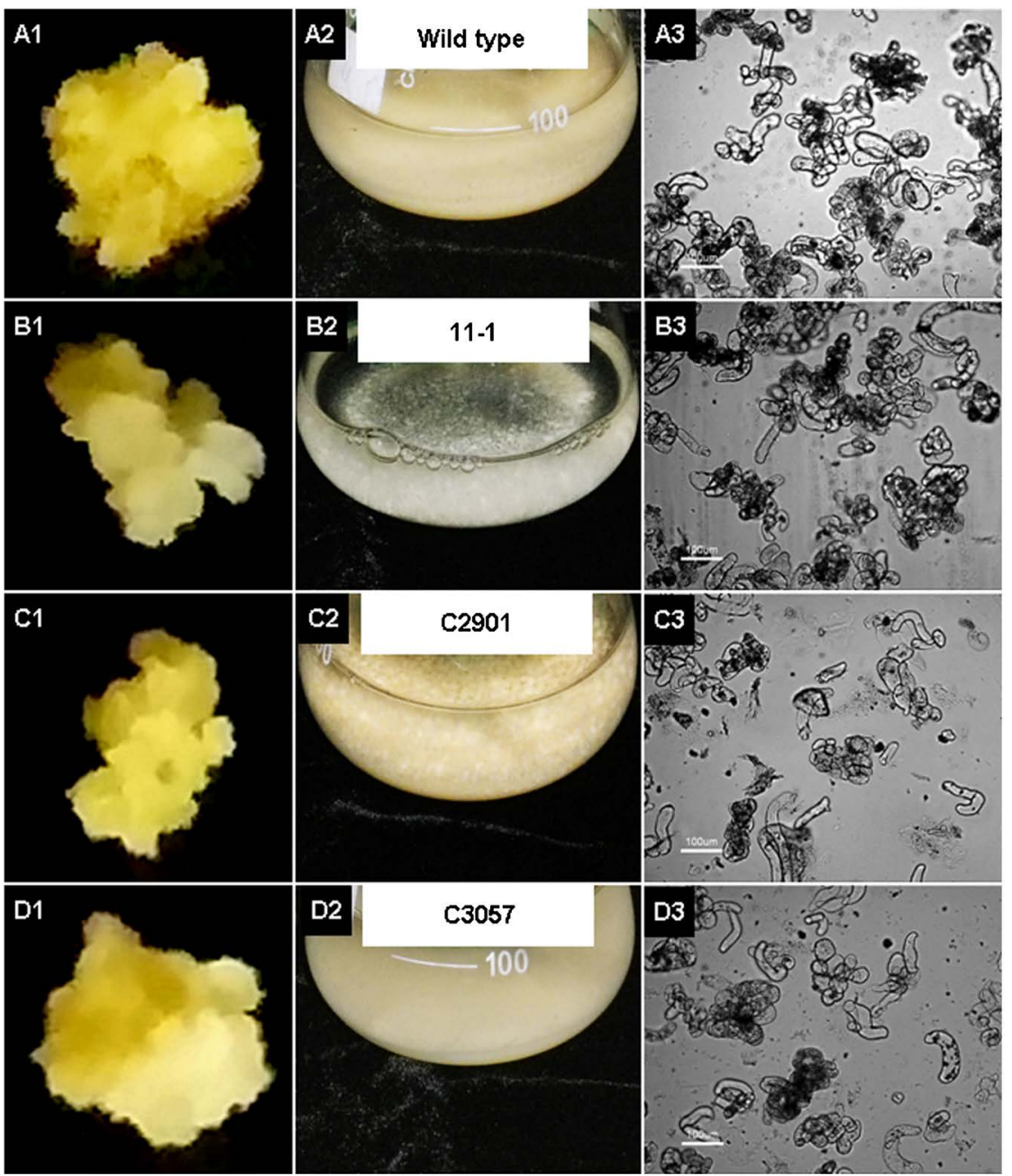




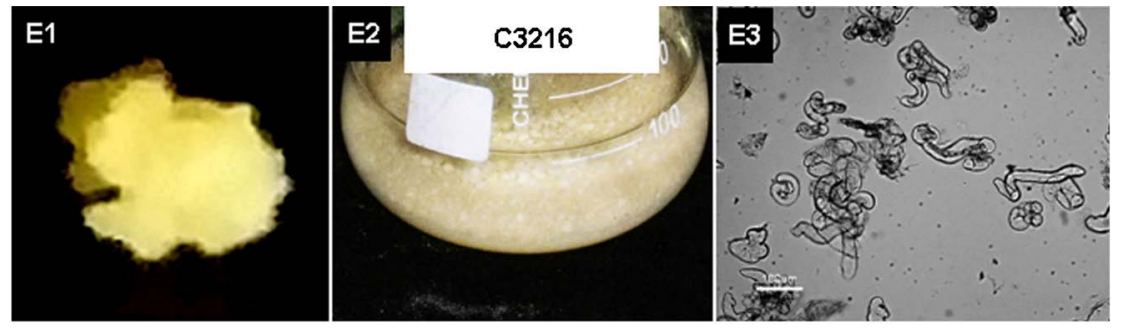

Figure S4. Cell suspension cultures of wild type (WT) and transgenic wheat. (A1-A3), wild type, (B1-B3) transgenic wheat lines 11-1, (C1-C3), C2901, (D1-D3), C3057 and (E1-E3), C3216. The calli for initiating suspension cultures (A1-E1), suspension cultures (A2-E2), and cell clusters in suspension cultures (A3-E3) were shown in the left, middle and right panels. WT cultures were grown in wheat induction media, cultures of transgenic wheat were grown in selection media. Cell clusters (A3-E3) in suspension cultures were examined and images were captured under inverted microscope. Scale bar $=100 \mu \mathrm{m}$.
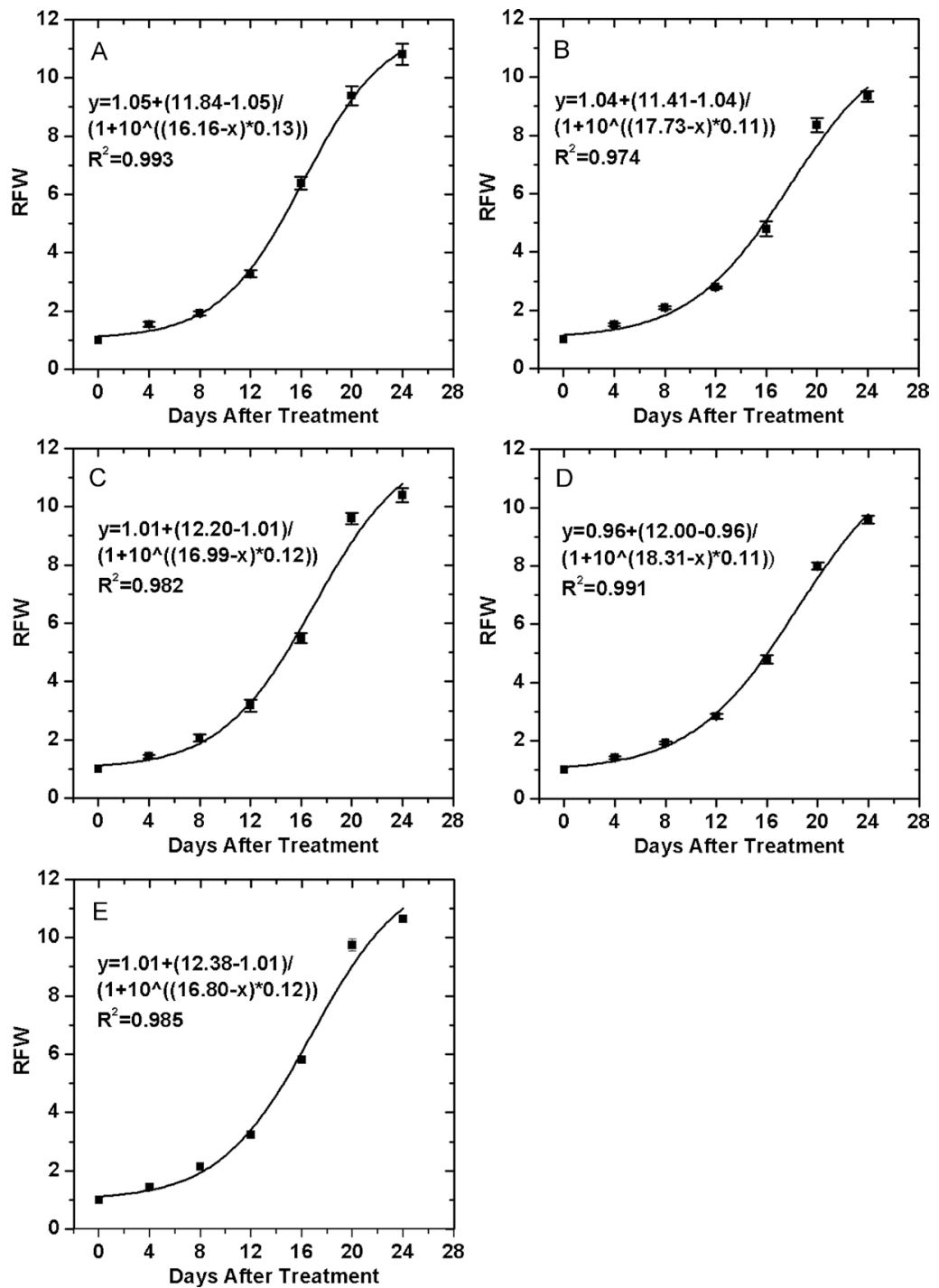

Figure S5. Growth curve of suspension cultures. (A) Wild type (WT), (B) wmCENH3-RFP transgenic wheat line 11-1, (C) C2901, (D) C3057 and (E) C3216. Fresh weight of suspension cells of WT, 11-1, C2901, C3057 and C3216 were measured at 0, 4, 8, 12, 16, 20 , and $24 \mathrm{~d}$ after treatment. The relative fresh weights (RFWs) of the five suspension lines were calculated based on the formula in the section of Materials and Methods and fitted to the DoseResp Model using an OriginPro8 software. Vertical bar represents standard errors $(n=3)$. 


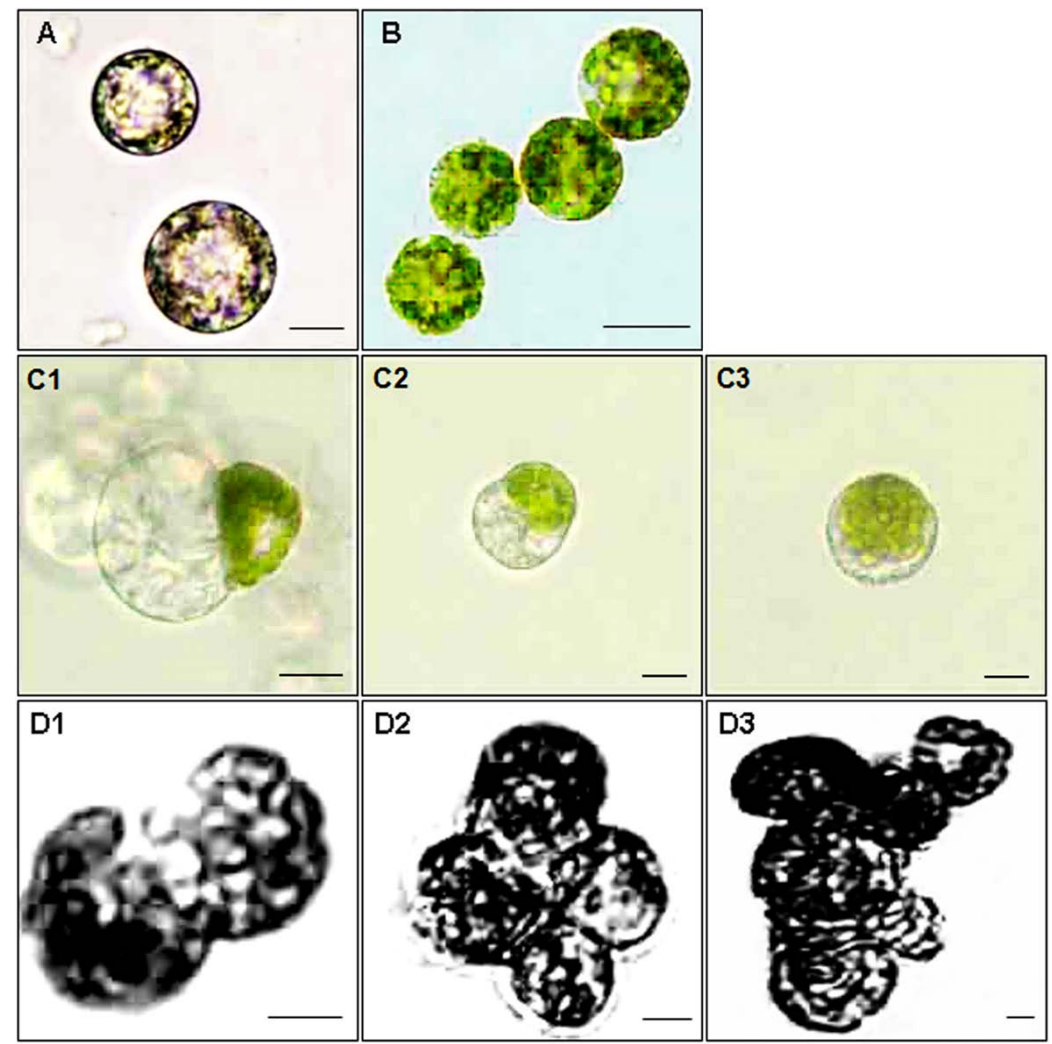

Figure S6. Wheat $\times$ maize somatic hybridization. (A) Protoplasts isolated from suspension cell of a wmCENH3-RFP transgenic wheat line C3216. (B) Protoplasts isolated from leaf mesophyll cells of ZmCENH3-YFP transgenic maize seedlings. (C) Fusion cells of wheat $\times$ maize observed at 1-2 d after fusion (DAF). (D) The growth of hybrid cells at 10 DAF (D1), 20 DAF (D2) and 30 DAF (D3). Scale bar $=20 \mu \mathrm{m}$.
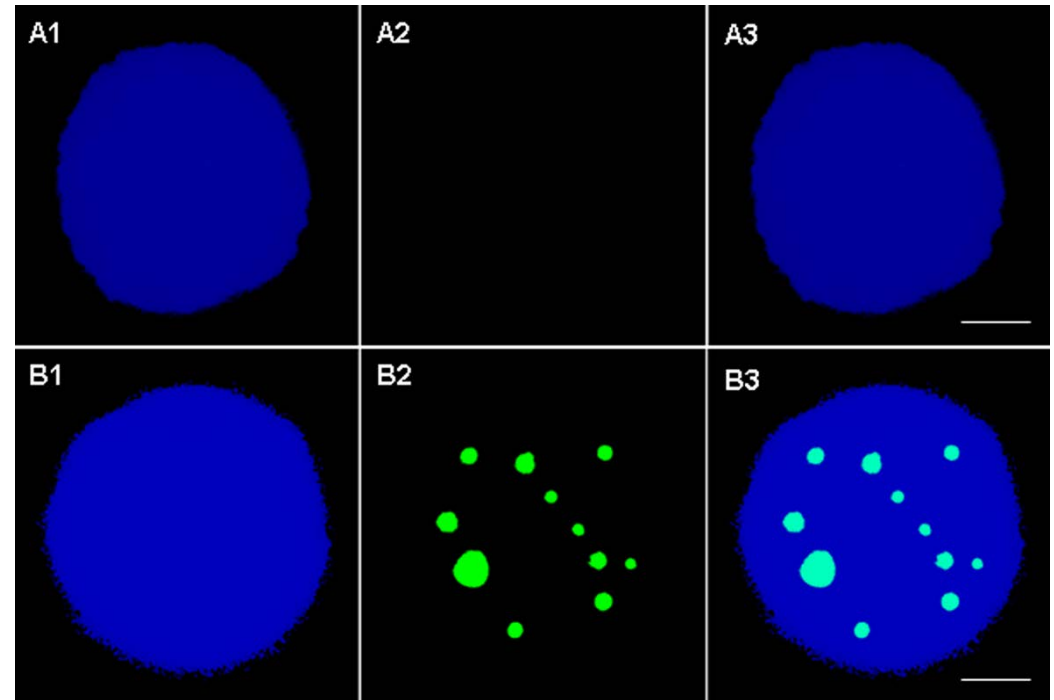

Figure S7. Detection of ZmCENH3-YFP with a green fluorescence protein (GFP) antibody in nuclei of ZmCENH3-YFP maize. (A1-B1) DAPI-stained nuclei from wild type (WT) and ZmCENH3-YFP transformed maize. (A2-B2) The immunostaining of ZmCENH3-YFP proteins in the nuclei from WT and ZmCENH3-YFP maize by rabbit anti-GFP primary antibody and FITC anti-rabbit secondary antibody. (A3-B3) Merged images of DAPI stained nuclei and ZmCENH3-YFP protein detected by immunostaining analysis. WT wheat was used as a negative control. Scale bar $=5 \mu \mathrm{m}$. 